Portland State University

PDXScholar

1979

\title{
An evaluation of parent education and parent group therapy as treatment components for child abusers
}

Jane Susan Crawford

Portland State University

Follow this and additional works at: https://pdxscholar.library.pdx.edu/open_access_etds

Part of the Cognitive Behavioral Therapy Commons, and the Psychology Commons Let us know how access to this document benefits you.

\section{Recommended Citation}

Crawford, Jane Susan, "An evaluation of parent education and parent group therapy as treatment components for child abusers" (1979). Dissertations and Theses. Paper 2928.

https://doi.org/10.15760/etd.2925

This Thesis is brought to you for free and open access. It has been accepted for inclusion in Dissertations and Theses by an authorized administrator of PDXScholar. Please contact us if we can make this document more accessible: pdxscholar@pdx.edu. 
AN ABSTRACT OF THE THESIS of Jane Susan Crawford for the Master of Science in Psychology presented August 8, 1979. Title: An Evaluation of Parent Education and Parent Group Therapy as Treatment Components for Child Abusers. APPROVED BY MEMBERS OF THE THESIS COMMITTEE:

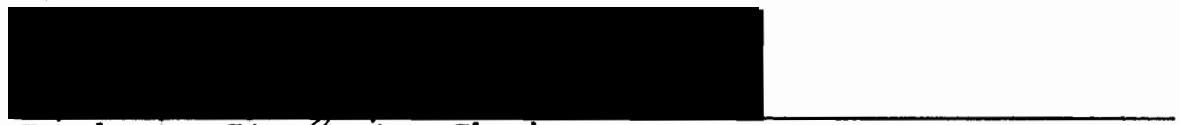
Barbara Stefart, Chairperson
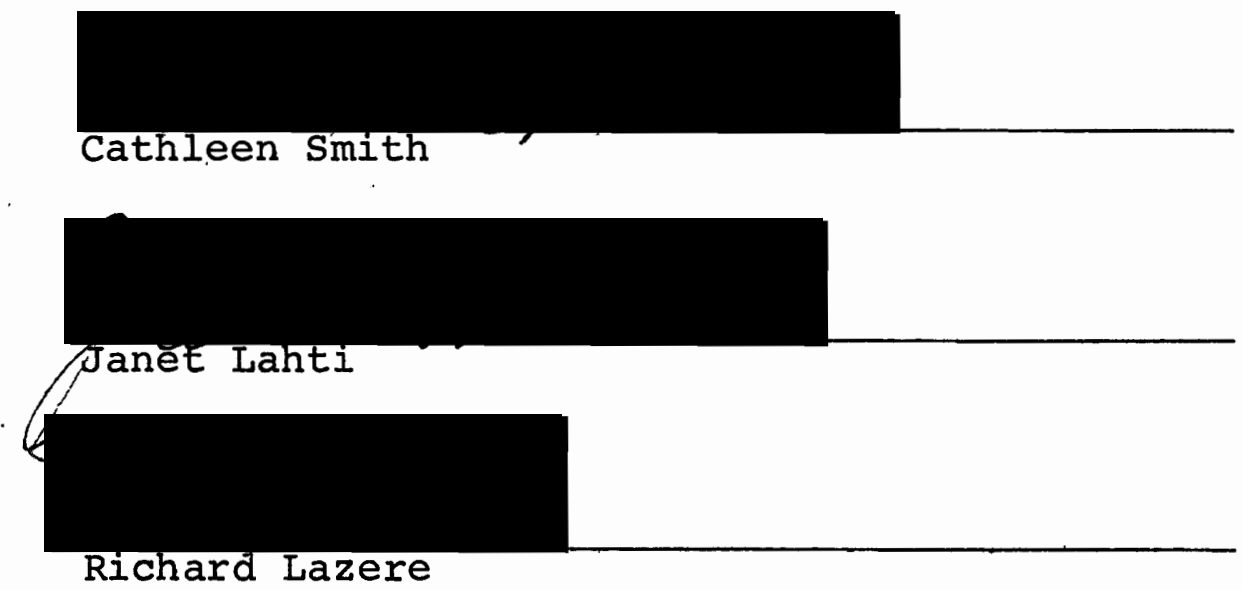

Treatment for child abusers was evaluated using two methods: reviewing three areas of literature and surveying practitioners.

First, literature regarding characteristics of child abusers was examined to establish if child abusers have certain definable characteristics. Literature regarding child abuse treatment programs offering parent education 
and/or group therapy was reviewed to establish a basis for the kinds of treatment offered for abusive parents. Iiterature regarding group dynamics issues was reviewed to establish a basis for determining what theoretical issues should be considered when conducting group therapy with. child abusers.

Second, a 73-item questionnaire was used to obtain practitioner opinions regarding what treatment components should be included in a child abuse treatment program; regarding group therapy for child abusers; and regarding parent education for child abusers. Child abuse and neglect programs were divided into two types of programs: Parent Education/Group Therapy (PE/GT) programs and Parents Anonymous (PA) self-help programs. Of the 2,227 programs listed in the Child Abuse and Neglect Programs manual, 200 programs were selected using a stratified random sample which resulted in two sample groups of $\mathrm{PE} / \mathrm{GT}$ practitioners and PA practitioners.

The literature review revealed inconclusive research findings regarding defining characteristics of abusive parents. However, certain associations that abusive parents may have been abused themselves as children, may have "low self-esteem" may have a larger than average number of children, may be more likely to be unemployed and may be socially isolated were suggested. Five child abuse treatment programs were reviewed and all programs suggested group 
therapy as one method of treatment for reducing social isolation of abusive parents. A review of group dynamics issues suggested that in working with abusive parents group size should be between 5 and 10 members, groups should be homogeneous, parents should be screened before attendance, and male-female co-therapists should lead the group.

Results of the questionnaire showed general agreement among practitioners regarding the areas of child abuse treatment program components, group dynamics issues, and parent education.

PE/GT practitioners indicated that of 14 child abuse treatment program components, 24-hour hotline, individual counseling, family therapy, and emergency child care were the most important components. PA practitioners indicated that a peer support network, daycare, 24-hour hotline, and parent education were the most important components.

Regarding the importance of 13 group dynamics issues and specifying which of two options on each issue was preferred, practitioners preferred smaller, homogeneous groups where male and female co-therapists direct the group such that the group serves as a support system. Voluntary attendance, the use of self-disclosure, and a broad focus were also preferred.

The total sample unanimously favored the inclusion of parent education in child abuse treatment programs. Practitioners generally agreed that parent education could be done 
in a variety of settings using a variety of methods.

The literature review and questionnaire results seemed to indicate that practitioners considered there was a crisis component to child abuse, that abusive parents lacked information regarding parent skills and child care, and that group treatment for child abusers alleviated social isolation. Guidelines for treatment with child abusers assimilating these results and recommendations for further research were given. 
AN EVALUATION OF PARENT EDUCATION AND PARENT GROUP THERAPY AS TREATMENT COMPONENTS FOR CHILD ABUSERS

by

JANE SUSAN CRAWFORD

A thesis submitted in partial fulfillment of the requirements for the degree of

\author{
MASTER OF SCIENCE \\ in \\ Psychology
}

Portland State University 
TO THE OFFICE OF GRADUATE STUDIES AND RESEARCH:

The members of the Committee approve the thesis of Jane Susan Crawford presented August 8, 1979.
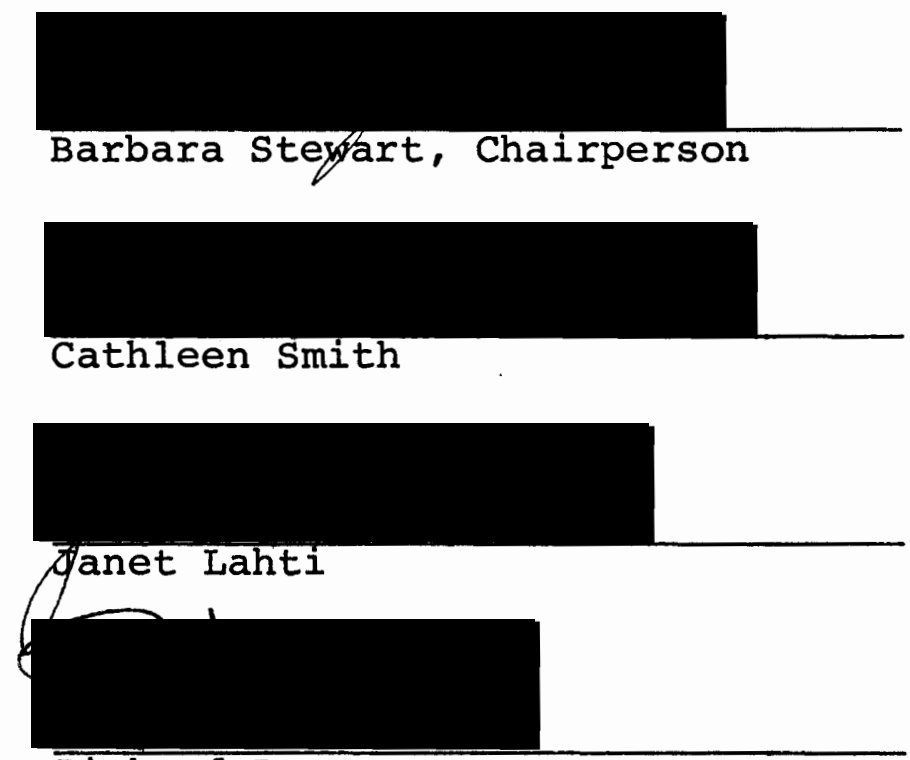

Richard Lazere

APPROVED :

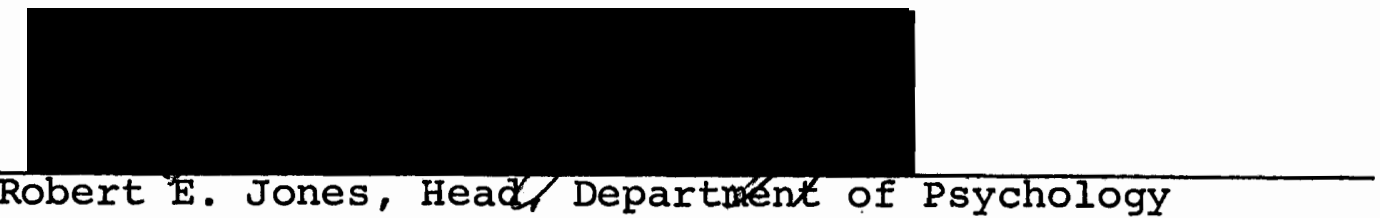

Robert $\mathrm{E}$. Jones, Head/ Department of Psychology

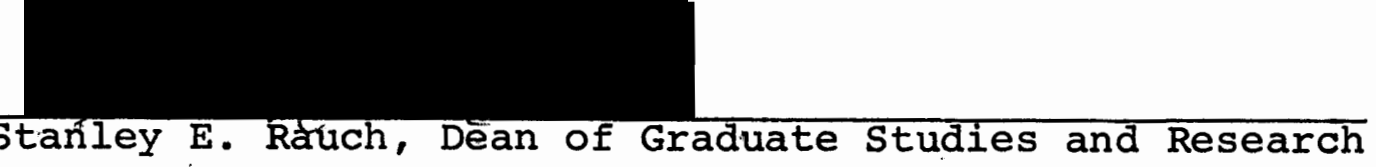


TABLE OF CONTENTS

PAGE

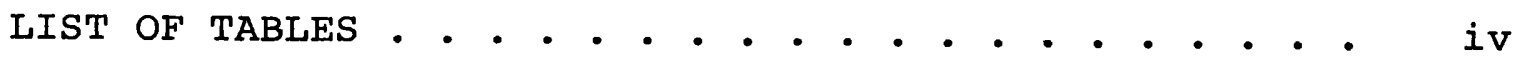

INTRODUCTION . . . . . . . . . . . . . . . . . . I I

REVIEW OF THE LITERATURE . . . . . . . . . . . . 6

Characteristics of Abusive Parents . . . . 6

Child Abuse and Neglect Treatment

Programs

Group Dynamics . . . . . . . . . . 26

METHOD . . . . . . . . . . . . . . . 42

RESULTS

Summary ................. . . 46

Child Abuse Treatment Program

Components . . . . . . . . . . .

Group Dynamics Issues . . . . . . . . 51

Theoretical Orientation of Conducting

Group Therapy . . . . . . . . . . 58

Parent Education ............. 58

DISCUSSION . . . . . . . . . . . . . 64

Child Abuse Treatment Program

Components . . . . . . . . . . 64

Group Dynamics Issues ............ 65

Parent Education . . . . . . . . . . 73

CONCLUSIONS AND RECOMMENDATIONS . . . . . . . . . 76

REFERENCES . . . . . . . . . . . ....... 84

APPENDICES . . . . . . . . . . . . . . 91 


\section{IIST OF TABLES}

TABLE

PAGE

1. SUMMARY TREATMENT PROCEDURES AND RELATED

PROBLEMS IN FIVE CHILD ABUSE AND

NEGLECT TREATMENT PROGRAMS • • • • • • .

2 PREFERENCES OF PRACTITIONERS REGARDING

IMPORTANCE AND INCLUSIONS OF COMPONENTS

IN A CHILD ABUSE TREATMENT PROGRAM . • . •

3 PREFERENCES OF PE/GT AND PA PRACTITIONERS

REGARDING IMPORTANCE OF COMPONENTS IN

A CHILD ABUSE TREATMENT PROGRAM • • • • . 50

4 PREFERENCES OF PRACTITIONERS REGARDING

CHOICE AND IMPORTANCE OF GROUP

DYNAMICS ISSUES • • • • • • • • • • •

5. PREFERENCES OF PE/GT AND PA PRACTITIONERS

REGARDING CHOICE AND IMPORTANCE

OF GROUP DYNAMICS ISSUES • • • • • • • . 55

6 PREFERENCES OF PRACTITIONERS REGARDING

THEORETICAL ORIENTATIONS OF

CONDUCTING GROUP THERAPY • • • • • . •

7 PREFERENCES OF PE/GT AND PA PRACTITIONERS

REGARDING THEORETICAL ORIENTATIONS

OF CONDUCTING GROUP THERAPY 
LIST OF TABLES (Continued)

TABLE

PAGE

8 PREFERENCES OF PRACTITIONERS REGARDING

SETTINGS FOR CONDUCTING PARENT

EDUCATION . . . . . . . . . . . 60

9 PREFERENCES OF PE/GT AND PA PRACTITIONERS

REGARDING SETTINGS FOR CONDUCTING

PARENT EDUCATION . . . . . . . . . . 60

10 PREFERENCES OF PRACTITIONERS REGARDING

THEORETICAL ORIENTATIONS FOR

CONDUCTING PARENT EDUCATION . . . . . . 61

11 PREFERENCES OF PE/GT AND PA PRACTITIONERS

REGARDING THEORETICAI ORIENTATIONS

FOR CONDUCTING PARENT EDUCATION • • • . 61

12 PREFERENCES OF PRACTITIONERS REGARDING

COMPONENTS OF PARENT EDUCATION . . . . . 62

13 PREFERENCES OF PE/GT AND PA PRACTITIONERS

REGARDING COMPONENTS OF PARENT

EDUCATION . . . . . . . . . . . 63

14 GUIDELINES FOR TREATMENT WITH CHILD

ABUSERS . . . . . . . . . . . 76 


\section{INTRODUCTION}

There are many facets to the problem of child abuse and neglect. One of these is identifying and defining child abuse in the legal sense and determining its consequences for the parent and child involved. Katz, Ambrosino, McGrath, and Sawitsky (1976) reviewed the research in this area in an effort to reach a legal definition of the child abuse problem. Naturally there is also the medical aspect of child abuse and neglect. Helfer (1976) reviewed the literature in this area in terms of the role that medicine plays in identification, physical effects on the child, and prevention.

Another facet of child abuse and neglect is understanding the causes of the problem. Generally there have been three approaches to understanding child abuse (Parke \& Collmer, 1975): (1) the psychiatric or psychodynamic model of child abuse, which focuses on the psychological functioning of the abusive parent; (2) the sociological model of abusive parents and the ways they deal with this environment; and (3) the social-situational model, which stresses family interaction patterns within the particular environment of the family. Friedman (1976) also reviewed the psychosocial research and summarized these approaches and drew conclusions similar to those of Parke and Collmer (1975). 
Yet another facet in the area of child abuse and neglect is treatment. Treatment can be specifically for the abused child, the abusive parent, or, more generally, for the family in which abuse is a problem. Yet, while child abuse and neglect is receiving more public attention and concern, little is known about which treatment services are most effective and what kinds of workers should provide these services (HEW, 1971, pg. 1).

This thesis is concerned with treatment for child abusers, specifically in the areas of group therapy and parent education. The purpose of the thesis is to examine several research questions concerning treatment for child abusers .

First, as a starting point for examining treatment, existing programs offering group therapy and/or parent education are reviewed. These programs include self-help groups such as Parents Anonymous, programs which use either group therapy or parent education as their primary treatment method, such as Boston's Parents' Center, and total treatment programs, such as Circle House where treatment is for the abused child, the abusive parent, and the family as a unit.

Second, after establishing a basis for the kinds of treatment offered, the thesis attempts to determine opinions of practitioners in the field regarding components of a child abuse treatment program. Should components offering 
crisis services, counseling services, and child care services all be included? Should there be an emphasis or is there a preference for some types of services over other types of services by practitioners working with child abusers?

Third, regarding the specific child abuse treatment program component of group therapy, the thesis attempts to determine opinions of practitioners regarding group therapy for child abusers. What issues regarding group structure, group leadership, and group dynamics are important when working with this population, according to practitioners in the field? Is there a preferred theoretical orientation when conducting group therapy with child abusers according to practitioners?

Finally, regarding the specific child abuse treatment program component of parent education, the thesis attempts to determine opinions of practitioners regarding parent education for child abusers. What method should be used when educating abusive parents?. Is there a preferred theoretical orientation according to practitioners? Is the setting of this education important? What should parent education for child abusers consist of, according to practitioners in the field?

To provide a theoretical framework for the research questions and to examine what constitutes effective treatment, the thesis uses two research methods. First, to 
identify theoretical issues and to summarize previous and current research in the area of treatment for child abusers, literature is reviewed in three areas. (1) Characteristics of abusive parents are examined to determine if child abusers do, in fact, have certain definable characteristics. If so, these characteristics may suggest what constitutes effective treatment for this population. (2) Documented child abuse treatment programs are reviewed to provide information regarding what treatments are currently available and which of these treatment types are actually used. (3) Group dynamic issues are explored as a basis for determining what theoretical issues should be considered when conducting group therapy and how these issues can be evaluated in terms of the special population of abusive parents. These literature review areas of characteristics of abusive parents, child abuse treatment programs, and group dynamic issues form the first method used in the thesis to determine what constitutes effective treatment for child abusers. The other method used to evaluate effective treatment is a survey of practitioners. The survey instrument was developed by the author.

This survey consists of a 73-item questionnaire that was mailed to 200 Child Abuse and Neglect Program directors. The questionnaire is based on the three groups of literature already described and my own experiences as a Parents Anonymous Sponsor. Questionnaire respondents are classified 
into two samples. One sample includes therapists who conduct group therapy and/or parent education with child abusers. The other sample includes Parents Anonymous sponsors. Responses of these two groups to the questionnaire will be compared.

The thesis is organized into the following sections. First, to examine the research questions regarding existing child abuse treatment programs, and opinions of practitioners in the field regarding child abuse treatment program components, group therapy, and parent education; literature pertaining to the characteristics of child abusers, child abuse treatment programs, and dynamic issues is reviewed. Second, the methods used to obtain practitioners' opinions on these same issues are detailed. This section includes a description of the sampling, subjects, survey instrument, and procedure. Third, the results of the questionnaire are summarized añd evaluated. Then follows a discussion of interpretation of these results, conclusions, recommendations for working with child abusers, and suggestions for further research. Finally, references are given and there are appendices containing a copy of the survey instrument, frequency distributions of questionnaire answers, and a summary of comments made by questionnaire respondents. 
REVIEW OF THE LITERATURE

Characteristics of Abusive Parents

In an effort to understand child abuse, and hopefully prevent it, researchers have tried to classify abusive parents in terms of both personality attributes and socioeconomic characteristics. The purpose of reviewing the literature regarding characteristics of child abusers is to determine if any conclusions have been reached regarding these characteristics and if these conclusions indicate what types of treatment should be available for child abusers.

Generally, research in this area has involved several problems. Many studies have been done with limited or unrepresentative samples and no control groups (Friedman, 1976; Gelles, 1977; Parke \& Collmer, 1975). Many attributes of abusive parents are based on clinical observation alone. Also, most research is ex post facto, making it difficult to determine whether potential abusers can be determined before the onset of abuse. Another limitation of current research is that the data are based on abusive parents who have been detected and reported. So, lack of data on unreported abusive parents has resulted in researchers trying to understand the causes of child abuse on reported cases only. It might be more accurate to say 
that attributes reported are only those that characterize child abusers who have been detected (Gelles, 1977).

Some hypothetical characteristics of child abusers, not yet statistically definable, included impulsivity and low frustration level (Fontana, 1971). Steele (1975) described abusive parents as having low self-esteem, and a lack of empathy regarding their children. The Parents Anonymous Chairperson-Sponsor Manual (1975) also described abusive parents as having low self-esteem and being manipulative. The well-controlled but small study by Melnick and Hurley (1969) revealed that abusive mothers in this study had lower self-esteem, less need to give nurturance, higher frustration of need dependence, and less family satisfaction. The researchers cautioned against too much generalization, however, since the samples were small and composed mainly of lower-class blacks.

While there is not a consensus regarding personality attributes of abusive parents, there is a consensus that whatever these attributes, most abusive parents are not psychotic (Spinetta \& Rigler, 1972; Steele, 1975). Kempe (1973) stated that less than $10 \%$ of abusive parents are psychotic.

Another characteristic attributed to abusive parents is that they were abused themselves as children (Fontana, 1971; Parents Anonymous Chairperson-Sponsor Manual, 1975; Paulson \& Blake, 1969; Spinetta \& Rigler, 1972; Steele \& 
Pollock, 1968). For the most part, researchers agree that abusive parents learned patterns of aggressive behavior as children, were not nurtured, and therefore are incapable of nurturing their own children. This results in an endless cycle of abuse that continues on with each new generation. Friedman (1976) disagrees with this viewpoint, however, contending that it seems for the most part to be based on clinical observations rather than on well-designed research studies.

Gelles (1977) seemd to find a middle ground and states that there is an association between a parent's history of abuse as a child and his or her own abusive patterns, with $30 \%$ to $40 \%$ of all abusers having abusive backgrounds. This does not mean that all people who grow up in an abusive environment are pre-disposed to be child abusers; however, there is a tendency to recreate one's childhood and the more a person experiences and supports the use of violence and views it as normal and acceptable, the more likely he or she is to resort to violence as an adult (Gelles, 1977). Abusive parents also seem to be socially isolated. Parents Anonymous (1975) sees this isolation as a primary difficulty for abusive parents. Parke and Collmer (1975) report that Lenoski, using a research design which matched abusive with nonabusive parents, found approximately $80 \%$ of the abusive families preferred to resolve crises alone, in contrast to approximately $40 \%$ of the nonabusive parents 
who sought assistance in time of crisis. Lenoski also found that $87 \%$ of the abusive parents who had telephones had unlisted numbers. This was true for only $12 \%$ of the nonabusive parents. Gelles (1977) also described an association between those families which do not have continuing relationships outside the family and those families involved in abusive incidents. Gelles cited a study done by Newberger, Reed, Daniel, Hyde, and Kotelchuck (1975) in a state whose welfare system would not pay for telephones. By using a cluster analysis method they found that whether a family had a telephone or not was the most important factor in predicting abusive behavior by the parent.

Because of the methodological problems mentioned earlier, the association between social class and child abuse remains unclear. It is consistently believed that child abuse occurs in all socioeconomic levels (Elmer, 1967; Gelles, 1977; Paulson \& Blake, 1969). Gil (1970) indicated that the higher amount of stress put on families of lower socioeconomic status creates a higher incidence of abuse. Gelles (1977, p. 64) also points out that there tends to be an "association in cases where people of low socioeconomic status experience a high degree of stress."

The particular economic phenomenon of unemployment seems more clearly related to child abuse. Gil (1970) reported that while approximately $12 \%$ of fathers in his study were unemployed at the time of reported abuse, only 
52.58 of the fathers in his study were employed for the whole year before the abuse incident. One theory incorporating this finding is that because the fathers spent more time with their children, more abuse by fathers occurred. Nevertheless, there does tend to be an association between unemployment and child abuse (Gelles, 1977, p. 64).

Finally, parents who have more than the average number of children seem more likely to become abusers (Elmer, 1967; Gelles, 1973; Gil, 1970; Young, 1964). Gelles (1973, 1977) found that when looking at 10 factors relating parents and their characteristics, such as age of parents, income, education, occupational prestige, number of children, resources, and family size, the best indicator of abuse was the number of children in the family; the larger the family the more violence used by the parents. But while more children in a family seems to be associated with child abuse, it is possible that parents who are unable to judge adequately the number of children they can properly care for may, in addition, be potentially abusive (Parke \& Collmer, 1975, p. 20).

In summary, a number of characteristics can be associated with abusive parents. Certain personality attributes such as "low self-esteem" have been suggested, but not statistically demonstrated as indicative of abusive parents. Social isolation and the possibility that abusive parents were abused themselves as children is another association, 
as well as a large number of children in the family and unemployment within the family.

Child Abuse and Neglect Treatment Programs

The next section of literature review, Child Abuse and Neglect Treatment Programs, attempts to determine if treatment programs for child abusers integrate any of the suggested characteristics of abusive parents into their treatment methods.

This section of the literature review outlines alternative child abuse and neglect treatment programs and describes specifically the types of treatment offered to abusive parents and their families within these programs.

A computer search done in 1.978 and an additional literature review revealed a lack of data regarding treatment programs. While many programs serve abusive parents and their children, descriptions of what constitutes effective treatment is minimal. Furthermore, many program descriptions that were researched contained little detail regarding treatment itself. Typically, more information is given regarding how to initially recognize child abuse and make available treatment options. However, information regarding application of these treatment options is largely unavailable.

Therefore, the five programs described here are only illustrations of three types of treatment programs: 
self-help groups, parent group therapy/parent education programs, and total child abuse treatment programs. These particular five programs were selected because written reports on them were available and because these reports were detailed enough to allow some evaluation of treatment methods and applications. Consequently, the reader should use caution in generalizing treatment for child abusers based only on procedures employed in these five programs. These programs include: (1) self-help groups, represented by Parents Anonymous; (2) parent group therapy/ parent education programs, illustrated by the Parent's Center Project and UCLA Neuropsychiatric Institute, and (3) total treatment programs which offer therapy for parents, children, and the family as a whole, illustrated by Circle House and the Extended Family Center. All programs will be described in terms of community setting and philosophy, client characteristics, treatment and staffing, clinical observations of effectiveness, and problem areas.

The purpose of reviewing these programs here is to evaluate treatment for abusive parents in terms of the aforementioned characteristics of abusive parents and also to establish treatment modes as a basis. for the survey instrument in this thesis. Following the program descriptions will be a summary of treatment intervention techniques in the area of working with abusive parents. 
Self-Help Group: Parents Anonymous

Community setting and philosophy. Parents Anonymous

(PA) is a self-help organization for child abusers with approximately 500 chapters representing over 4,000 parents across the nation. PA tries to provide a safe, supportive environment for parents in which they can. work through problems, learn from each other, and learn to support each other. PA recognizes six forms of abuse: physical abuse, physical neglect, emotional abuse, emotional neglect, verbal abuse, and sexual abuse (PA, Chairperson-Sponsor Manual, 1975).

Client characteristics. As a self-help organization, parents who attend meetings are often self-referred. However, as PA gains in popularity and recognition, some parents are mandated to attend meetings by child protective agencies and the courts.

Treatment and staffing. Some PA groups help maintain a 24-hour hotline in their areas for parents to call during times of crisis or to get information about PA. The major focus, however, is on the self-help group which is open to all parents, who can come to as many or as few meetings as they wish.

The group is led by the Chairperson and a sponsor. The Chairperson is a parent from the group and is elected by the group to serve in this role. The sponsor usually has a clinical psychology or social work background and assists 
the Chairperson in sorting out group dynamics, lends emotional support to the Chairperson, and serves as a professional resource for the group. PA stresses, however, that the Chairperson is the group leader.

This method of the parent leading the group and the Sponsor supporting the Chairperson results in roles that are described as a parent surrogate for the Chairperson and a grandparent surrogate for the sponsor. The PA chapter then becomes a kind of surrogate family for its members with the Chairperson serving as an easily identifiable model and peer as well (Parents Anonymous Chairperson-Sponsor Manual, 1975). This modeling by the Chairperson is important since a high priority is placed on disclosing abuse and emotional problems in PA groups, and in the meetings parents are helped to identify the situations and feelings that have led to abuse. As an extension of the supportive group environment, group members and the group leaders exchange phone numbers so parents can come out of isolation and have a contact during times of loneliness or crisis (Parents Anonymous Chairperson-Sponsor Manual, 1975).

Clinical observations. The PA organization regards abusive parents as having low self-esteem, as being isolated, and as being manipulative in their dealings with others. It is felt that the supportive group atmosphere alleviates these problems and helps the parents deal with the feelings underlying their abusive behavior towards their children. 
Problem areas. Many PA chapters are unstable due to the fact that $\mathrm{PA}$. does not screen parents before they attend a group to see if they are suitable for the group. Therefore, parents may not fit into a group situation and may only attend a single time. Also, since PA groups are open they may at times become too large. They are then divided so a chapter will never be closed to new members. Many times group members are "lost" when a group is divided. Open groups also present the problem of having new members at every meeting. At times this can affect the cohesiveness of the group since long-term members will be in a different stage of dealing with their abuse problems.

Other problems are transportation to and from group meetings and offering child care while the parents meet.

Parent Education/Group Therapy Programs: The Parents' Center Project Boston, Massachusetts

Community setting and philosophy. The Parents' Center in Boston was established in 1968 and serves as a center to help keep families with pre-school age children intact while the child and the parents receive treatment and until the child is of school age. Parents involved at the center are abusive or are suspected of abuse and the center is used as an alternative to out-of-home placement (Bean, 1971, p. 278). Client characteristics. Center clients consist of families where an incident of abuse or suspected abuse has occurred and where the parents are amenable to help and 
willing to attend group therapy.

Treatment and staffing. One treatment component is supervised daycare for the children which is staffed by child care workers. The purpose of daycare is to provide parents with relief from responsibility for their children ardalso as a place for parents to observe and participate in a supervised setting with their children.

Group therapy is the major treatment method for parents at the Center since the staff feels that the intense transference and countertransference in child abuse cases make these clients difficult to treat individually (Bean, 1971, p. 280). Group meetings led by male-female cotherapists allow the parents to share experiences about themselves, their children and marriages, and annoyances and gratification they have concerning the daycare staff. Clinical observations. Staff reports regarding content of the group therapy meetings reveal that few of these parents had normal relationships with their own parents. In addition, there seems to be a prevalence among these child abusers of physical complaints, reports of elective surgery, and use of medication.

Galdston (1975) suggests a pattern of fear of success based on other observations. For instance, many parents lived happily with a partner until a new child spoiled the relationship or they lived reasonably happily in a marriage until they were overwhelmed by problems outside, such as 
economic problems. But as soon as these things improved, the marriage crumbled. Attempts to help the parents succeed by involving agencies for homemaking, job training, employment, or parent counseling seemed to intensify the failure (Galdston, 1975, p. 378).

Problem areas. Finding child care workers who can respond without anger and defensiveness to the testing being done by the parents when they are involved with daycare has been a problem.

Parent Education/Group Therapy Programs: UCLA Neuropsychiatric Institute Los Angeles, California

Community setting and philosophy. At this Institute a team of therapists works with abusive parents using group therapy, child care education, and home visits.

Client characteristics. Treatment is for parents who physically abuse or neglect their children. Parents are referred mainly from the Department of Social Services, with occasional referrals from the UCLA Center for Health Sciences, Parents Anonymous, and attorneys. A few parents are self-referred after hearing of the program through the media. The criterion for joining the group is that both parents attend and exceptions are made in cases where only one parent is living in the Los Angeles area.

Treatment and staffing. The abusive parents at the Institute are simultaneously involved in group therapy as well as child care education. There are two therapy groups 
at the Institute, both led by male-female co-therapists. The therapists in one group are a clinical psychologist and a psychiatric nurse. The therapists in the other group are a child psychiatrist and a public health nurse. In both groups the nurses provide the child care education and home visits. Theoretically, the group treatments can be described as multidisciplinary, multitheoretical, and eclectic. Techniques incorporated into the group are confrontation, encouragement of parents reliving or experiencing significant events, and stimulation of the group process (Paulson \& Chaleff, 1973, p. 39).

Child care education is given during the first part of group therapy. This parent training is devoted to information giving about practical measures related to development and child care. More specifically, subjects such as feeding, toilet training, discipline, and sibling rivalry are covered, as well as the information given on normal physical and emotional development. In connection with this child care education, home visits are made by the nurse co-therapist whenever they are requested.

A Child Management Class is also offered at the Institute. This class uses Patterson and Gullian's Living With Children (1974), a book which stresses behavior modification techniques.

Clinical observations. Therapists at the Institute feel that group therapy with abusive parents is aided by 
having child abuse as the identified reason for being in the group. It is felt that this homogeneity contributes greatly to acceptance, group cohesiveness, and identification (Paulson \& Chaleff, 1973, p. 39).

In the area of group leadership, therapists at the Institute describe the male-female co-therapists as providing "parent surrogates" for the abusive parents. The parent surrogate roles modeled by the therapists allow for the abusive parents to be involved for the first time with noncondemning, non-punishing adults who will be intimate and emotionally sharing. with them (Paulson \& Chaleff, 1973, p. 40). For most parents the male-female co-therapist relationship reconstructs the primary family unit. This results in abusive parents learning to relate to the therapists and being able to challenge their authority while being assured of acceptance. Acceptance of the abusive parent by their peers within the groups is also an important group dynamic (Paulson \& Chaleff, 1973, p. 39).

Problem areas. No problem areas were revealed in the reports of the program at the UCLA Neuropsychiatric Institute.

Total Treatment Program:

Circle House Denver, Colorado

Community setting and philosophy. This residential treatment program for abusive families is an alternative to separating the abused child from his family. Started by 
the National Center in 1974, Circle House provides 24-hour services for up to four residence families. The treatment. center includes the Family unit for parents and children and the Child Care Unit which provides care for children under court-ordered protection and for their siblings as needed. Families stay in residence from four weeks to several months and enter circle House after a court hearing regarding child abuse. The facilities include a private sitting-bedroom for each couple, and a separate bedroom for each child. A kitchen, dining room, family room, laundry facilities, and craft area are shared. Breakfast is made by each individual family; a cook fixes lunch and shares the dinner tasks with the families.

The goal of Circle House is to provide a warm, emotional, supportive environment for families and one that is predictable as well for the children (Alexander \& Rodenheffer, 1976, p. 242).

Treatment and staffing. Formal treatment for parents is multifaceted and includes individual psychotherapy, weekly marital therapy, and evening group therapy which is led by male-female co-therapists. These formal treatments continue for about three months after the family leaves. Child psychologists conduct formal parent-child interaction sessions where child management techniques are modeled and discussed along with information about normal child development. Child care education for parents often focuses 
directly on the parent-child relationship, with the parents' contact with the child being closely supervised by the staff. Gradually this supervision is reduced and by the end of residency, parents have assumed full child care.

Formal treatment for children includes therapeutic sessions suited for their age group.

Clinical observations. Staff members feel that the most important aspect of Circle. House is that it keeps the family together and relieves the parents of child care during stress and crisis, thus keeping the child safe from further abuse. Another advantage of this residential treatment is that fathers and siblings are included in treatment. Staff members feel that their inclusion is necessary for successful intervention with abusive families, and also feel that the parent-child interaction sessions are essential in changing the parents' relationship with their children (Alexander \& Rodenheffer, 1976, p. 247).

Also, the 24-hour care results in much needed information about abusive families while at the same time allowing parents to see the healthy interactions that staff members have with the abused children (Alexander \& Rodenheffer, 1976, p. 248).

Problem areas. Problems arise when parents interpret staff intervention with their child as disapproval of their own parenting. This problem results in the parent becoming angry at both the staff member and the child. The separate 
Child Care Unit was created to resolve this problem.

Total Treatment Program:

Extended Family Center

San Francisco, California

Community setting and philosophy. The Extended Family

Center was established in February, 1973 as a treatment

center for abused children and their parents. The Center,

as its name implies, is a place for parents to develop the kind of resources an extended family would provide and thus offer an alternative to placing abused children in foster care.

Client characteristics. The Center serves parents who physically abuse or neglect their children and these abused children. Families are referred by local hospitals, public health, mental health and social welfare agencies, private physicians, public health nurses, the courts, and the University of California Medical Center.

Treatment and staffing. The Center's services include daycare, home visits, group therapy, occupational group therapy, individual counseling, and a hotline.

As a community program committed to hiring community people, the Extended Family Center's staff consists of three nonprofessional social workers or lay therapists, one occupational therapist, and two parent consultants who were once abusive parents but now are able to provide good care for their children. In addition, there are five child care workers, one head teacher, two administrative assistants, 
and a director who was a social worker with five years experience in working.with abusive parents.

The children in daycare are separated into three age groups for care and are required to attend a minimum of four hours per day. Within each group, age-related skills are stressed with an emphasis on attention from the teachers who give one-to-one support.

Parent treatment at the Center is based on groups. While individual counseling is available, it is felt that the parents themselves, with support from the professional staff, provide their own treatment by learning to give support and understanding to each other. Formal group therapy topics include marital and financial problems, past experiences, feelings about children, and discussions of abusive acts. Transactional analysis in relation to the group process is used in this therapy and the group is led by a male social worker and female parent consultant.

While more informal, group occupational therapy has worked extremely well with abusive parents because it offers a means of assessing the parents' functioning, this treatment has also revealed that the parents are unable to complete projects, have difficulty relating to authority, have an unwillingness to try new things, and in general lack self-confidence (TenBroeck, 1974, p. 5). Occupational therapy has several components including individual craft projects and a social skills group led by the occupational 
therapist and the parent consultant. This means that while in the group each parent works on a project. Contracts are made with the parents for each project to make sure that parents realize the time involvement. The socialization group aspect of the therapy emphasizes a safe environment for developing social skills and learning that the need for adult contact outweighs the need for isolation (Coleman, 1974 , p. 415).

Other specific treatment for parents requires them to pick up their children from daycare.

Clinical observations. Staff observations report that formal therapy rarely brings about change; instead change occurs because of the relationships of parents with parents and parents with staff (TenBroeck, 1974, p. 6).

Another observation is that the kinds of support services provided by the center are extremely demanding of the staff since the parents tend to be very dependent.

Problem areas. There have been some problems with parents and the daycare. Parents are concerned about the lack of physical discipline and while they are relieved not to have responsibility for their children during this time, they are threatened by the loss of control and/or love of the child (TenBroeck, 1974, p. 5).

Summary

In conclusion, there seems to be a consensus regarding treatment for abusive parents that ends their isolation and 
meets their dependency needs.

All of the programs clinically report the isolation of abusive parents as referred to in the description of characteristics of abusive parents. Each program attempts to meet this need by providing a support system, usually by means of group therapy.

An added benefit of groups is that they are helpful in lessening the emotional burden of staff members as the group begins to meet the needs of the parents. Also, all of the programs describe use of co-therapists/leaders, which also alleviates some of this burden. So, the group process is clinically regarded as promoting change and growth in abusive parents. As observed by staff members at the Extended Family Center, this happens apart from formal therapy.

Some groups are also used for teaching specific skills, such as parent skills at the UCLA Institute and occupational skills at the Extended Family Center. Other groups such as PA self-help groups encourage parents to take responsibility for their own treatment (NCCAN, 1977).

A recurring problem, as reported by those programs which include daycare, is that parents feel threatened and feel a loss of control when others take responsibility for their children. Yet, while the parents do not always approve of child care methods used by the staff, they nevertheless are relieved when others assume responsibility for 
their children.

Two of the programs provide a comprehensive treatment center. Two major problems exist with this approach: the high cost in resources and staff time over an extended period and the creation of too much client dependence. However, it would be realistic to say that the needs of the parents must be met before they are able to meet the needs of their children. While centers have been shown to be reasonably effective with some families, it has not been shown that this approach is more effective than other treatment concepts. Generally, no one model has been shown conclusively to be more or less effective than any other (NCCAN, 1977).

The treatment programs described offer a variety of treatment components. (See Table 1) In summary, these include daycare, therapeutic daycare, 24-hour hotline, 24-hour on-call staff member, group therapy, individual counseling, occupational therapy, marital counseling, parent education, parent-child interaction sessions, family therapy, and information referral. These treatment components were also used as a basis for construction of the survey instrument.

\section{Group Dynamics}

Since group therapy or parent education was included in all of the program descriptions, programs selected for 
TABLE 1

SUMMARY TREATMENT PROCEDURES AND RELATED PROBLEMS IN FIVE CHILD ABUSE AND NEGLECT TREATMENT PROGRAMS

\begin{tabular}{|c|c|c|c|}
\hline & Crisis Services & Child Services & Counseling Services \\
\hline $\begin{array}{l}\text { Parents } \\
\text { Anonymous }\end{array}$ & 24-hour hotline & $\begin{array}{l}\text { Babysitting during } \\
\text { group meeting }\end{array}$ & \\
\hline $\begin{array}{l}\text { Boston } \\
\text { Parents ' } \\
\text { Center }\end{array}$ & & Daycare & Parent Group Therapy \\
\hline $\begin{array}{l}\text { UCLA Neuro- } \\
\text { psychiatric } \\
\text { Institute }\end{array}$ & & & $\begin{array}{l}\text { Parent Group Therapy } \\
\text { Home Visits }\end{array}$ \\
\hline $\begin{array}{l}\text { Extended } \\
\text { Family } \\
\text { Center }\end{array}$ & 24-hour hotline & $\begin{array}{l}\text { Daycare } \\
\text { Emergency daycare }\end{array}$ & $\begin{array}{l}\text { Occupational Group } \\
\text { Therapy } \\
\text { Parent Group Therapy } \\
\text { Individual Psycho- } \\
\text { therapy } \\
\text { Home Visits }\end{array}$ \\
\hline Circle House & $\begin{array}{l}\text { 24-hour on-call } \\
\text { staff }\end{array}$ & $\begin{array}{l}\text { Daycare } \\
\text { Child Therapy }\end{array}$ & $\begin{array}{l}\text { Individual Psycho- } \\
\text { therapy } \\
\text { Parent Group Therapy } \\
\text { Marital Therapy } \\
\text { Parent-Child Inter- } \\
\text { action Sessions } \\
\text { Family Therapy }\end{array}$ \\
\hline
\end{tabular}


TABLE 1 (Continued)

SUMMARY TREATMENT PROCEDURES AND RELATED PROBLEMS IN FIVE CHILD ABUSE AND NEGLECT TREATMENT PROGRAMS

Staffing

Problem Areas

\begin{tabular}{|c|c|c|}
\hline $\begin{array}{l}\text { Parents } \\
\text { Anonymous }\end{array}$ & $\begin{array}{l}\text { Former abusive parent as } \\
\text { primary group leader } \\
\text { (Chairperson); parapro- } \\
\text { fessional or professional } \\
\text { providing assistance to } \\
\text { Chairperson (Sponsor) }\end{array}$ & $\begin{array}{l}\text { Transportation to meetings } \\
\text { Babysitting } \\
\text { Open groups - don't screen } \\
\text { parents; groups become too } \\
\text { large }\end{array}$ \\
\hline $\begin{array}{l}\text { Boston } \\
\text { Parents } \\
\text { Center }\end{array}$ & $\begin{array}{l}\text { Professional child care } \\
\text { Workers and therapists }\end{array}$ & $\begin{array}{l}\text { Providing child care workers who } \\
\text { understand child abuse }\end{array}$ \\
\hline $\begin{array}{l}\text { UCLA Neuro- } \\
\text { psychiatric } \\
\text { Institute }\end{array}$ & Professional therapists & \\
\hline $\begin{array}{l}\text { Extended } \\
\text { Family } \\
\text { Center }\end{array}$ & $\begin{array}{l}\text { Lay therapists } \\
\text { Parent consultants } \\
\text { Professionals }\end{array}$ & $\begin{array}{l}\text { Parents sometimes feel threatened } \\
\text { by loss of control over child } \\
\text { when child is in daycare }\end{array}$ \\
\hline $\begin{array}{l}\text { Circle } \\
\text { House }\end{array}$ & Professionals & $\begin{array}{l}\text { Parents sometimes resent staff } \\
\text { interference when parent is } \\
\text { in interaction with child }\end{array}$ \\
\hline
\end{tabular}


the thesis survey were also those that offered group therapy and/or parent education. Also, since group therapy as a treatment modality has many alternatives, this section of the literature review will explore group therapy and group dynamic issues.

Group therapy in various forms is a part of each of the aforementioned child abuse treatment programs. There is little description in the reports, however, regarding specific group therapy issues. From the reports it is evident that the groups meet weekly and have co-therapist/ leaders. However, there are many other aspects of group dynamics such as group structure, group leadership, and group process that can be defined. These issues will be examined in terms of the described child abuse treatment programs, characteristics of abusive parents, and also as a basis for the group dynamics questions in the survey instrument used to collect data for this thesis. The purpose of reviewing group dynamics issues, here, is to determine if there is a consensus in the research regarding different group dynamic issues. In addition, how these issues may be applied to group therapy with child abusers will be discussed.

\section{Group Structure}

There are certain mechanical and practical considerations in conducting group therapy. These include the size of the group, voluntary attendance vs. mandatiory attendance, 
screening parents before group attendance, homogeneous vs. heterogeneous groups, closed access vs. open access groups, and time-limited vs. open-ended groups.

Size of the group. The optimum group size for group therapy seems to be between five and 10 members (Fried, 1971; Hartford, 1971; Lazarus, 1968; Yalom, 1970). Factors to be considered regarding size are member participation and absenteeism. Too large a group might not allow everyone to participate while too small a group does not allow a wide enough range of interaction. If absenteeism is a factor, group size should be large enough for the group to function even if a couple of members are absent (Hartford, 1971, p. 169) .

Voluntary vs. mandatory attendance. This issue is not often referred to within the group dynamic literature. However, because of the laws regarding child abuse it is important to consider here. Since some abusive parents have been "convicted" of child abuse, they are often mandated to attend specific sorts of therapy, including group therapy. This causes motivational problems for these parents who have not sought group therapy and also increases their sense of being visibly punished while others in the group may not.

Parents Anonymous chapters often have court-ordered parent participation. This presents unique problems for an organization which focuses on anonymity, since attendance 
records for these parents have to be kept.

Screening parents. There is a consensus in the literature regarding the necessity of screening clients in general before placing them into a group. Many researchers feel this is important so the therapists can understand the potential group member's thought processes and also to see if the person will benefit from group treatment (Fried, 1971).

Hobbs (1951) lists those who should be excluded from group therapy. These people are those who are very hostile and aggressive, people who have continuously close contact with each other outside the group, and those who cruelly use what psychological sophistication they have when interacting with others.

PA does not screen parents so that meetings are always open for any parents who want to attend and so that they do not have to be interviewed before attendance. A problem can arise if individuals attend the group who are excessively hostile or so dependent that they take up all of the group's time.

The Parents' Center screens parents in the sense that the parents understand what is expected of them in the program and are willing to be involved in the group. The UCLA Institute screens parents in the sense that both parents have to attend if they live in the Los Angeles area. The two comprehensive treatment programs do not screen parents 
specifically for group attendance. If parents participate in the total program, they are involved in group therapy as well.

\section{Homogeneous vs. heterogeneous groups. Homogeneous} groups are those where there exists a common identified reason for attendance, whereas heterogeneous groups are composed of people who have different reasons for attendance. Yalom (1970, p. 193) reports that heterogeneous groups have some advantage over homogeneous groups for intensive, interactional group therapy. But, homogeneous groups jell more quickly, become more cohesive, offer more immediate support, and are better attended. Lubin (1976) cautions that homogeneous groups may influence therapists to spotlight the "common problem" while ignoring the individual's other needs. Obviously, groups included in the previously mentioned programs are homogeneous, with child abuse as the identified, common problem.

Closed-access vs. open-access groups. Open groups add new members frequently, sometimes at every meeting, while closed groups do not add members once the group has begun. There are advantages and disadvantages to each kind of group and there does not seem to be a consensus regarding this issue in the research, although therapists are reported as having a preference.

Some think that closed groups are more advantageous because group composition is constant and research is easier 
to do in closed groups (Bremmer \& Shostrom, 1968; Kadis, Krasner, Winick \& Foulkes, 1965). Some therapists indicate that a closed group is particularly good for a group that is also homogeneous since the common goal is resolution of a common problem.

Disadvantages of closed groups are that they may become too small if members have to drop out and that they create more dependency problems among members and cause separation problems when the group ends. PA contends that the biggest problem of closed groups is their inaccessibility when parents need them.

Advantages of open groups are the influx of new ideas, beliefs, and values and a change in composition which can erase old problems and boost morale (Hartford, 1971, p. 135). Also, new members stimulate the group to re-work competition within the group and the group may become more cohesive in doing this (Bremmer \& Shostrom, 1968).

A disadvantage of open groups as reported by PA is their instability, which, if very pronounced, can limit cohesiveness.

Time-limited vs. open-ended groups. Time-limited groups meet for a predetermined number of sessions while open-ended groups can continue indefinitely.

Time-limited groups are particularly appropriate for groups that have a defined format such as parent education (Bremmer \& Shostrom, 1968). In time-limited groups, members 
are less likely to develop intense relationships (Hartford, 1971). However, the time limit may encourage a group to resolve problems quickly.

This could be particularly advantageous in group therapy with abusive parents if they can resolve their abuse problems. Yet, resolution of abuse problems might require development of close relationships, which is more likely in open-ended groups. Again, PA prefers open-ended groups to insure that any parent can attend at any time and have their needs met.

\section{Group Leadership}

Issues concerning group therapists/leaders include the number and sex of the leaders and also whether or not they are professionals or nonprofessionals.

Self-help vs. professionally led groups. Self-help groups began partly as a result of a lack of professionals and also in reaction to an authority structure which can be perceived as restrictive and not conducive to individual growth (Yalom, 1970, p. 325).

PA emphasizes the self-help aspect of these organizations which focuses on a parent model, or Chairperson, as the primary leader. The sponsor serves as the professional therapist, but is to remain in the background.

One-therapist/leader vs. co-therapists/leaders. Lubin (1976) describes co-therapy as a place for an inexperienced therapist to learn about group process. Bremmer and 
Shostrom (1971) also describe co-therapists as having different functions, one as the facilitator and one as the interpreter/summarizer. Several of the aforementioned programs report the need for co-therapists to lessen the emotional load of a single therapist when working with abusive parents in groups.

Co-therapists who are both professional, both nonprofessional, or one of each. PA (1975) reports that it is easier for abusive parents to join a group when the parents can identify with one of the group leaders, in this case the Chairperson. The Extended Family Center follows the PA model and also uses a parent model as one of the group leaders.

Male-female co-therapists vs. therapists of the same sex. Paulson and Chaleff (1973, p. 39) report that in working with abusive parents, having male-female cotherapists allows for group members to see the therapists as parent surrogates. This is important for parents who were abused, rejected or emotionally deprived by their own parents.

PA also regards the group leaders as surrogate parent figures, but does not make a sex distinction. With the exception of $\mathrm{PA}$, all of the previously described programs use male-female co-therapists indicating that in working with abusive parents having therapists of each sex is considered important. 
Group Process

Certain group dynamics issues refer to group process. These include the group as a support system, broad focus in the group as opposed to a narrow focus, self-disclosure, and group therapy with emphasis on the individual vs. group therapy with emphasis on the group.

Group as a support system. Group therapy provides a support system for individuals in terms of social contact, problem solving, and goal setting. Sherman (1964) states that the advantage of group treatment is involving people in the group process which promotes an understanding of the. factors that create their isolation. Group members see that they have similar problems and this perception encourages supportive behavior. At the same time, members become more aware of their own impact on people and become more sensitive to others.

Cartwright and Iippitt (1961) point out that the individual learns that if he is going to receive support he must give support. And, Collins, and Guetzhow (1964) report that individuals can learn that through the help of others they can attain their own individual goals.

Several of the aforementioned programs describe the peer support that group therapy provides for child abusers as a very important part of group treatment.

Broad focus vs. narrow focus. Groups with a broad focus discuss most anything members wish to, while groups 
with a narrow focus limit discussion to particular topics. For instance, parent education groups have a narrow focus if discussion concerns only parent education.

In all of the previously mentioned programs, there is a narrow focus if only child abuse is discussed. However, most groups permit discussion of other topics such as employment, housing, and so on as described by the Parents' Center. Self-disclosure (SD). It is through self-disclosure that much of the interpersonal learning in group therapy takes place, the "universality" of one's problems is established, and important data for feedback are revealed. If some members are able to risk SD others may follow suit (Allen, 1973, p. 313).

Allen (1973) reports that there is a relationship between the capacity for SD and social adjustment. Allen also points out that the therapist in a group can facilitate SD on the part of group members by initiating it. He also suggests that using co-therapists would allow one to become more of a participant in the group while using SD as a discretionary tool, while the other therapist could maintain a more interpretive role.

PA places high value in SD and indicates that SD is the first step in resolving abuse problems. The Chairperson serves as a model of self-disclosure.

Group therapy with individual emphasis vs. group therapy with group emphasis. Group therapy with emphasis 
on the individual is advocated by slavson and Wolf (1964) who state that emphasis should be on individual analysis enhanced by the group setting and not on the group and its dynamics. In addition, they see the leader-member relationship rather than the peer relationship as the all-important treatment factor (Lubin, 1976, p. 402) Group therapy with individual emphasis uses the group as a setting for, and facilitator of, individual therapy.

Group therapy with group emphasis focuses on the group process. Bion, Ezriel, and Whitar and Lieberman follow this approach and see the group as a place for the individual to resolve earlier experiences and learn different behaviors while reacting to the anxieties and changes presented by the group (Lubin, 1976). For instance, losing a member of the group could help members learn to cope with the anxiety of separation as well as release feelings regarding earlier separations. It is not clear from the program descriptions which school of emphasis is followed by each program.

\section{Summary}

This literature review has summarized characteristics of abusive parents, has described five child abuse and neglect programs, and has identified group dynamics issues in the treatment of child abuse. Certain conclusions concerning theoretical issues and previous research findings are particularly relevant for this thesis. 
Research findings regarding defining characteristics of abusive parents were inconclusive but certain associations were suggested.

(1) Abusive parents may have been abused themselves as children.

(2) Abusive parents may tend to have "low self-esteem."

(3) Abusive parents may be more likely to have a larger than average number of children. (4) Abusive parents may be more likely to be unemployed. (5) Abusive parents may be socially isolated.

In examining treatment options which were considered by the five described programs, one treatment method suggested for reducing the social isolation of abusive parents was group therapy. All of the programs included group therapy as a treatment option. Emphasis regarding the specific group therapy offered differed depending on the specific program. PA followed a self-help model. UCLA Neuropsychiatric Institute and Boston's Parents' Center used group therapy as the primary treatment component in their programs for abusive parents. Circle House and the Extended Family Center used group therapy as one of many treatment components in their total child abuse and neglect treatment programs.

Interpreting the group dynamics literature in light of the program descriptions, there appears to be a consensus regarding some group therapy issues with child abusers. It appears that optimum group size should be between five and 10 members. Homogeneous groups are preferred, suggesting 
that child abuse should be identified as the presenting problem for group attendance. It also appears desirable to have male-female co-therapists as group leaders. The group and the support system it provides seem to be very important in working with abusive parents.

The second research method used in this thesis, the survey of practitioners, was based on the preceding three areas of literature. It attempts to answer the research questions regarding practitioner opinions on what treatment components should be included in a child abuse treatment program, on group therapy for child abusers, and on parent education for child abusers. The following Method section explains how opinions of practitioners were obtained and compares these opinions to the research presented in the literature review. 


\section{METHOD}

$\underline{\text { Subjects }}$

The Child Abuse and Neglect Programs manual (U.S. Department of Health, Education and Welfare, U.S. Children's Bureau National Center on Child Abuse and Neglect, March, 1978) listing 2,227 programs was used to obtain a sample of 200 programs which included group therapy, parent education, or Parents Anonymous self-help groups as part of their counseling services.

The sampling design of this study included dividing the child abuse and neglect programs into two types of programs: Parent Education/Group Therapy (PE/GT) programs and Parents Anonymous (PA) programs. This division was based on the particular philosophy of PA which supports the right of parents to be anonymous and which emphasizes parent leadership through the model of a self-help group. PE/GT programs did not make these distinctions. The sampling division was also used to determine if there were in fact differences between responses of those who were PA Sponsors (the professional or paraprofessional group leaders) and those leaders in PE/GT programs. Using this PE/GT vs. PA dichotomy, a stratified random sample was selected.

The Child Abuse and Neglect Programs manual was first 
researched for those programs that directly offered group therapy and/or parent education. Parent Education was used as an inclusive term for programs that offered "child management classes" or parent education techniques such as "Parent Effectiveness Training." From the 627 programs that offered group therapy or parent education, 177 programs were selected randomly.

The Child Abuse and Neglect Programs manual was also researched for PA organizations or programs which offered PA. From the 72 entries that included Parents Anonymous, 23 PA programs were selected randomly.

\section{Survey Instrument}

The questionnaire sent to the 200 programs was divided into three sections and was constructed so as to include the issues identified as important in the review of the literature. (A copy of the survey instrument is in Appendix B.) The first section of the questionnaire asked for preferences regarding whether each of 12 components should be included in a child abuse treatment program. These components included crisis services such as a 24-hour hotline, child services such as daycare, and counseling services such as family therapy. The inclusion of two other components, home visits and parent education, was assessed in later sections of the questionnaire.

The second section of the questionnaire asked respondents to state their preferences and ratings of importance 
for each of 15 group dynamics issues as they applied to group therapy with abusive parents. These issues included those that referred to what goes on in a group, those that refer to group structure, or how the group is set up, and theoretical orientations regarding group therapy.

The third section of the questionnaire concerned parent education and asked for opinions regarding the settings in which parent education could be conducted, components of parent education such as discipline/setting limits, and theoretical orientations regarding parent education.

\section{Procedure}

Questionnaires were sent to the directors of the 200 programs selected. Directors were instructed to have the most experienced group therapists or parent education staff member fill out the questionnaire. Parents Anonymous questionnaires instructed Parents Anonymous Sponsors to respond. of the 23 questionnaires sent to Parents Anonymous Sponsors, fourteen $(61 \%)$ were returned. Of the 177 questionnaires sent to programs having group therapy and/or parent education, 72 (41\%) were returned. Of the returned questionnaires, $27 \%$ were only partially complete. Typically, one section of the questionnaire which covered procedures not included in the respondents' program was not completed; however, other sections of the questionnaire were usable. Follow-up letters were sent to program directors six 
weeks after initial mailing of the questionnaires. Enclosed postcards requested program directors to indicate whether the original questionnaire had been misplaced, whether it was currently being filled out, whether they no longer had a parent education program, group therapy, or Parents Anonymous program, or whether the questionnaire had been received but they did not wish to respond. (A copy of the follow-up letter and postcard are in Appendices $C$ and D.)

Respondents who indicated they no longer have PE/GT therapy programs included 228 of the original $177 \mathrm{PE} / \mathrm{GT}$ programs contacted. Likewise, $17 \%$ of the original PA programs were no longer in existence. 


\section{RESULTS}

This survey was intended to be descriptive so statistical tests in general were not performed except where it was desirable to infer differences between the Parent Education/Group Therapy (PE/GT respondents $(\underline{n}=72)$ ) and the Parents Anonymous (PA respondents $(\underline{n}=14)$ ) on particular variables.

Questionnaire results were determined by percentages for the yes/no questions and for the questions possessing the response format of extremely important, moderately important, slightly important, not at all important, and actually harmful.

For the questions where items were to be ranked as to their importance, the median rank for each item was calculated. These calculations allowed the items to be ordered regarding their importance based on the median response of the sample. The Mann-Whitney U Test was used to compare the two samples on selected items for the ranking questions. Questionnaire results were calculated for the total group as well as for the PE/GT sample and the PA sample separately. Original questionnaires and follow-up questionnaires returned after a reminder letter revealed little difference in responses. Consequently, all results are based on the combined original and follow-up questionnaires. 
Following is a summary of the findings. An elaboration of results follows this summary.

\section{Summary}

When asked to indicate which of 14 components were most important to include in child abuse treatment programs, practitioners in current treatment programs expressed the following:

(1) Parent Education/Group Therapy practitioners indicated that a 24-hour hotline, individual counseling, family therapy, and emergency child care were the four most important components to include.

(2) Parents Anonymous Sponsors expressed that a peer support network, daycare, a 24-hour hotline, and parent education were the four most important components to include.

When asked to indicate the importance of 13 group dynamics issues and to specify which of two options on each issue was preferred for treating child abusers, the practitioners strongly agreed on tine preferred option for eight of the issues. In general, preferences were in favor of smaller homogeneous groups where male and female cotherapists direct the group such that the group serves as a support system. In addition, voluntary attendance and the use of self-disclosure and a broad focus during group 
discussion were endorsed.

The total sample unanimously endorsed the inclusion of parent education in child abuse treatment programs. The current practitioners in child abuse treatment programs generally agreed that parent education could be done in a variety of settings and using a variety of methods.

An elaboration of these findings is reported in three sections. The first section summarizes responses to questions dealing with the inclusion and importance of components of a child abuse treatment program. The second section reports responses regarding preferences and importance of group dynamics issues. Theoretical orientations regarding group therapy are also summarized. The third section reports findings concerning parent education. This section focuses on practitioners' preferences regarding possible settings for parent education, theoretical orientations for parent education, and potential components of parent education.

\section{Child Abuse Treatment Program Components}

Table 2 summarizes the extent to which the total sample supports inclusion of 14 components in child abuse treatment programs. In addition, this table includes the ranking of importance of each component, as well as the percent of the sample rating the given components as "extremely important." of the 14 components, all but one (parent 


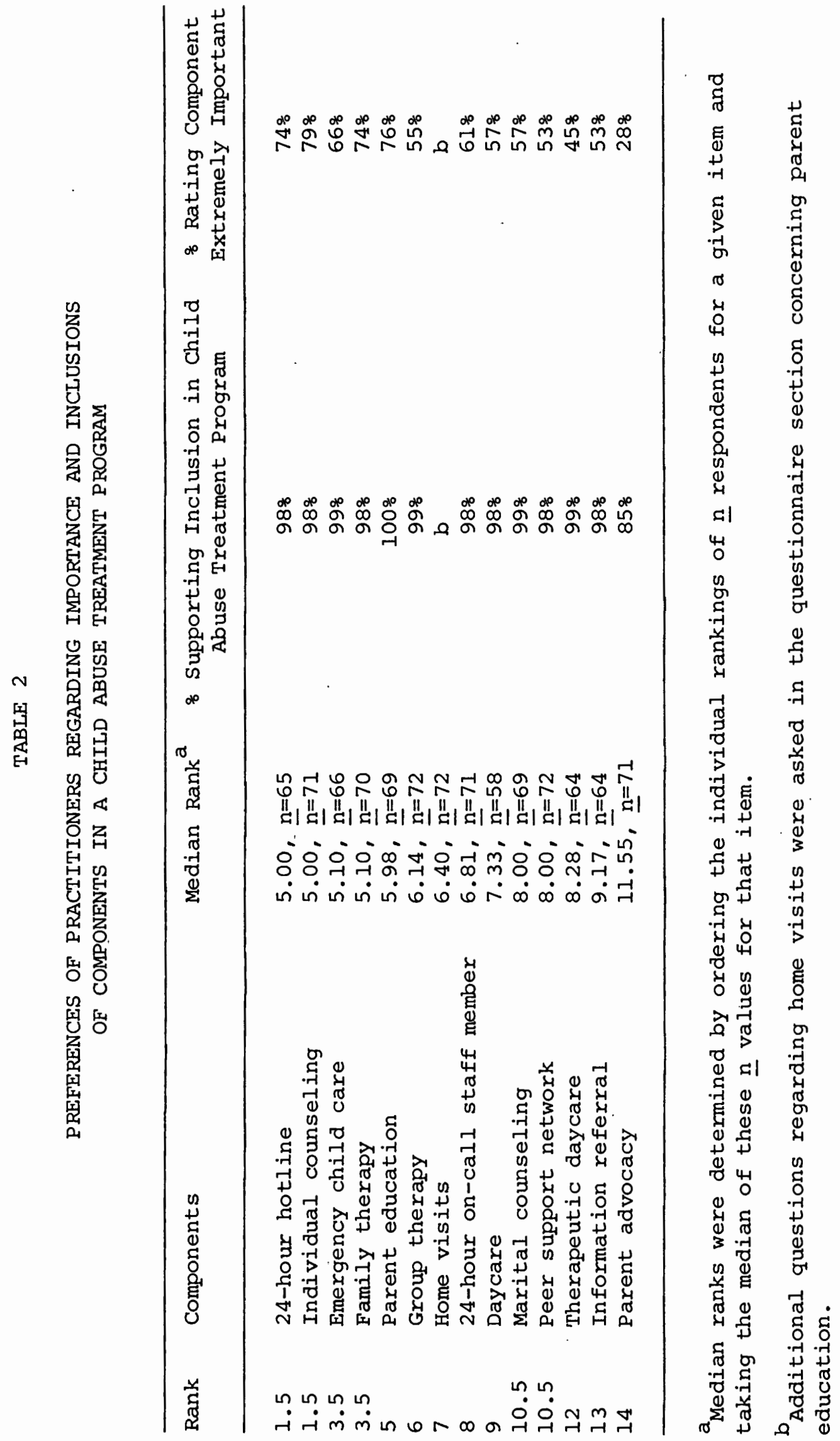


advocacy) are supported for inclusion by $98 \%$ or more of the sample. The five components ranked the highest in importance are 24-hour hotline, individual counseling, emergency child care, family therapy, and parent education. Parent advocacy was evaluated as least important.

Table 3 summarizes the extent to which the PE/GT sample and the PA sample each support inclusion of various components in a child abuse treatment program.

Rankings of importance for the two samples of $\mathrm{PE} / \mathrm{GT}$ and $P A$ were most similar in that:

(i) 24-hour hotline was ranked high by both samples.

(2) Emergency child care, group therapy, and home visits for both $\mathrm{PE} / \mathrm{GT}$ and $\mathrm{PA}$ samples were ranked moderately important.

(3) Therapeutic daycare was ranked low in importance by both sample groups.

The primary differences between the groups appeared to be regarding the importance of the peer support network and family therapy. Mann-Whitney U Tests comparing the differences between the two groups in ranking each of these components revealed significant differences (peer support, $z=-2.03, p<.05$; family therapy $z=-2.06, p<.05)$. The component of the peer support network was ranked higher in importance by the PA sample (median rank $=3.50$ ) than by the $P E / G T$ sample (median rank = 8.33). The importance of family therapy was ranked lower by the PA sample (median 
TABLE 3

PREFERENCES OF PE/GT AND PA PRACTITIONERS REGARDING IMPORTANCE OF COMPONENTS IN A CHILD ABUSE TREATMENT PROGRAM

Parent Education/Group Therapy Sample Medians

(1) 24-hour hotline (3.56, $\underline{n}=53$ )

(2) Individual counseling (4.60, $\underline{n}=58$ )

(3) Family therapy (4.88, $\underline{n}=54$ )

(4) Emergency child care (5.00, $\underline{n}=54)$

(5) Group therapy (6.11, $\underline{n}=59$ )

(6) 24-hour on-call staff (6.25, $\underline{n}=55$ )

(7) Home visits (6.33, $\underline{n}=59$ )

(8) Parent education $(6.75$ $\underline{n}=57$ )

(9) Marital counseling (7.00, $\underline{n}=57)$

(10). Daycare (8.17, $\underline{n}=54$ )

(11) Peer support netowrk (8.33, $n=59)$

(12) Therapeutic daycare

$$
\text { (8.50, } \underline{n}=56 \text { ) }
$$

(13) Information referral

$$
\text { (9.40, } n=58 \text { ) }
$$

(14) Parent advocacy

$$
\text { (11.75, } \underline{n}=57)
$$

Parents Anonymous Sample Medians

(1) Peer support network

$$
\text { (3.50, } \underline{n}=12)
$$

(3) Daycare $(4.5, \underline{n}=11)$

(3) 24-hour hotline (4.5, $\underline{n}=12$ )

(3) Parent education (4.5, $\underline{n}=12$ )

(5.5) Emergency child care $(6.0, \underline{n}=12)$

(5.5) Home visits (6.0, $\underline{n}=13$ )

(7.5) Group therapy (6.25, $\underline{n}=11$ )

(7.5) Parent advocacy (6.25, $\underline{n}=12$ )

(9) Information referral

$$
\text { (6.25, } \underline{n}=12 \text { ) }
$$

(10) Individual counseling

$$
\text { (7.25, } \underline{n}=13 \text { ) }
$$

(11) Therapeutic daycare

$$
\text { (8.5, } \underline{n}=12 \text { ) }
$$

(12) Family therapy (8.83, $\underline{n}=12$ )

(13) Marital counseling

$$
\text { (9.5, } \underline{n}=12)
$$

(14) 24-hour on-call staff $(10.00, \underline{n}=12)$ 
rank $=8.33$ ) than for the $\mathrm{PE} / \mathrm{GT}$ sample (median rank = 3.50). While the PA sample appeared to rank daycare and parent advocacy higher in importance and 24-hour on-call staff as lower in importance than the PE/GT sample, these differences were not significant.

\section{Group Dynamics Issues}

Table 4 indicates how each of 13 group dynamics issues was ranked in importance by the total sample. It also indicates the percentage of the total sample rating given issues as "extremely important" and "moderately important." In addition, this table indicates which of two options was the preferred choice of the majority of the sample along with the percentage of respondents choosing that option.

The six issues ranked highest in importance were:

(1) size of the group;

(2) the group as a support system;

(3) homogeneity vs. heterogeneity;

(4) voluntary attendance vs. mandatory attendance;

(5) self-disclosure; and

(6) broad focus vs. narrow focus.

The two issues of one therapist vs. co-therapists and malefemale co-therapists vs. co-therapists of the same sex were ranked lowest in importance. For the six issues ranked highest in importance and for the two issues ranked lowest in importance, there was strong agreement regarding the favored option. 


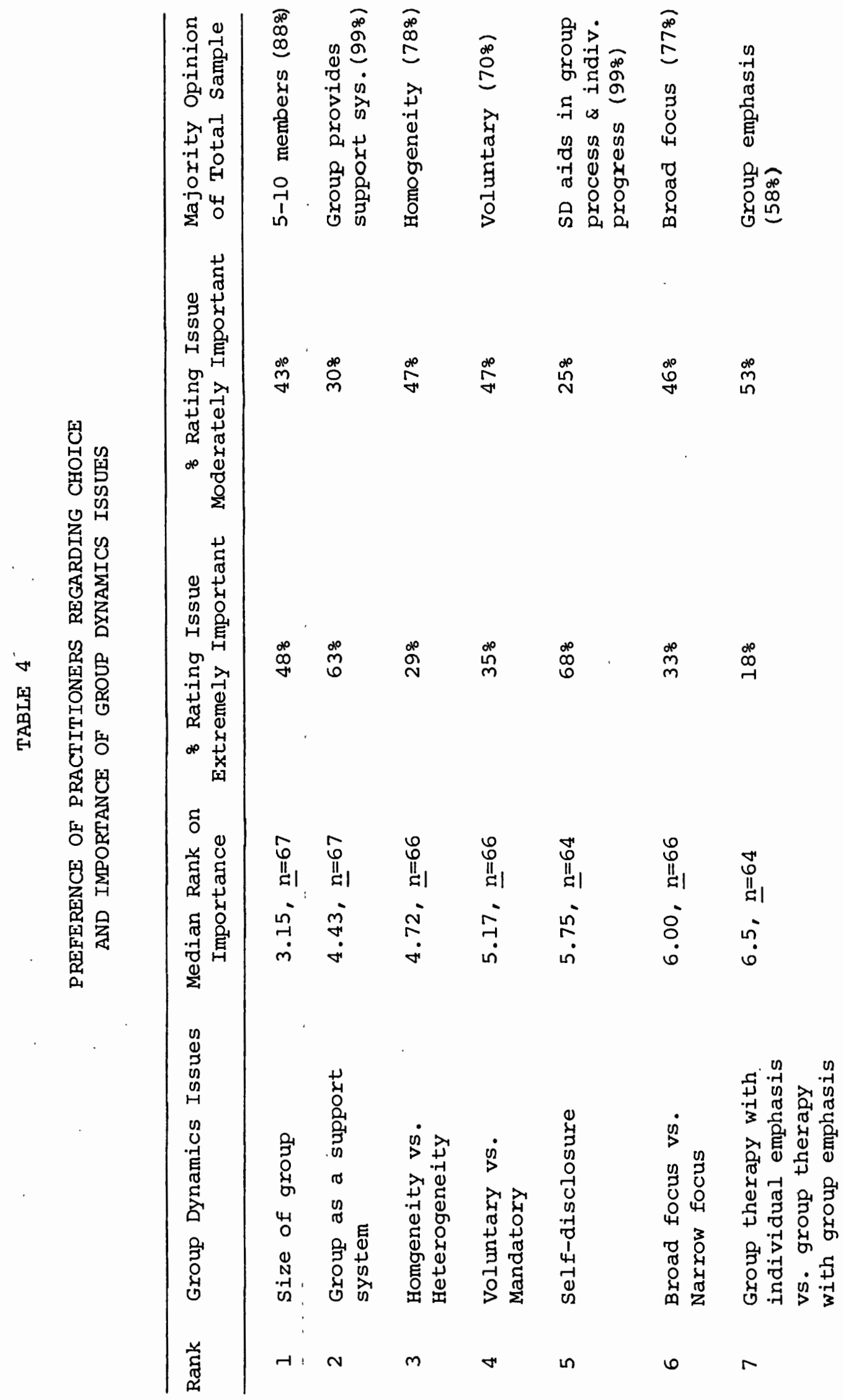




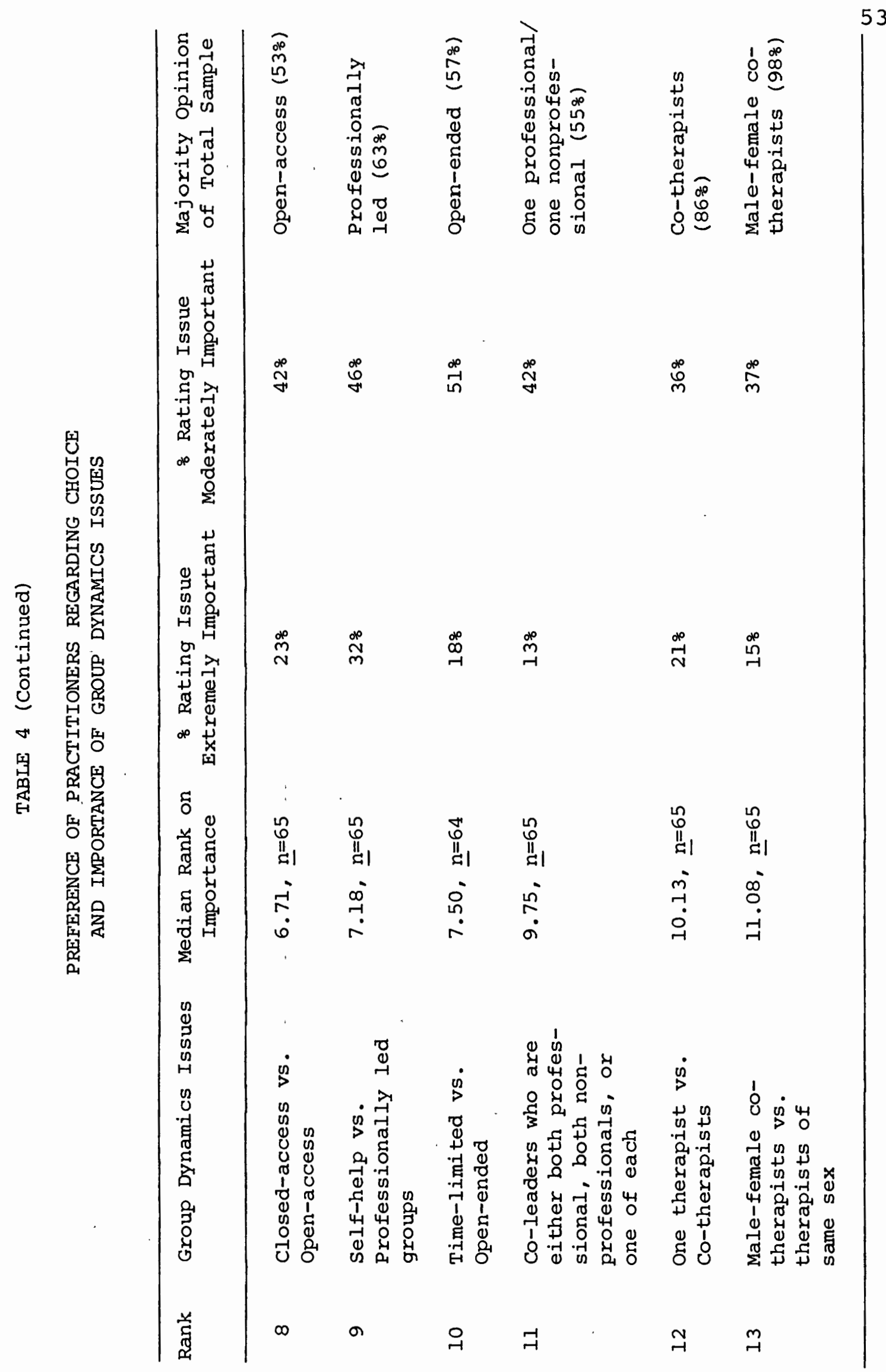


The group dynamics issues on which practitioners in current child abuse treatment programs clearly agreed are:

(1) The optimum group size was 5-10 individuals rather than a larger group.

(2) The group did serve as a support system.

(3) Homogeneous groups (i.e., child abuse as a common reason for attendance) were preferred over heterogeneous groups.

(4) Voluntary attendance was preferred over mandatory attendance.

(5) Self-disclosure aided in both the group process and individual progress.

(6) A broad focus of group discussion (i.e., issues not necessarily related to child abuse) was more desirable than a narrow focus.

(7) Co-therapists were preferred over a single therapist.

(8) Having male-female co-therapists was more desirable than having both therapists of the same sex. There is not a clear consensus regarding whether the emphasis of group therapy should be on the group process or on the individual. There appears to be a slight preference (55\%) for the co-therapists to include one professional and one nonprofessional.

Table 5 indicates how each of. 13 group dynamics issues were ranked in importance by the PE/GT sample and the PA 


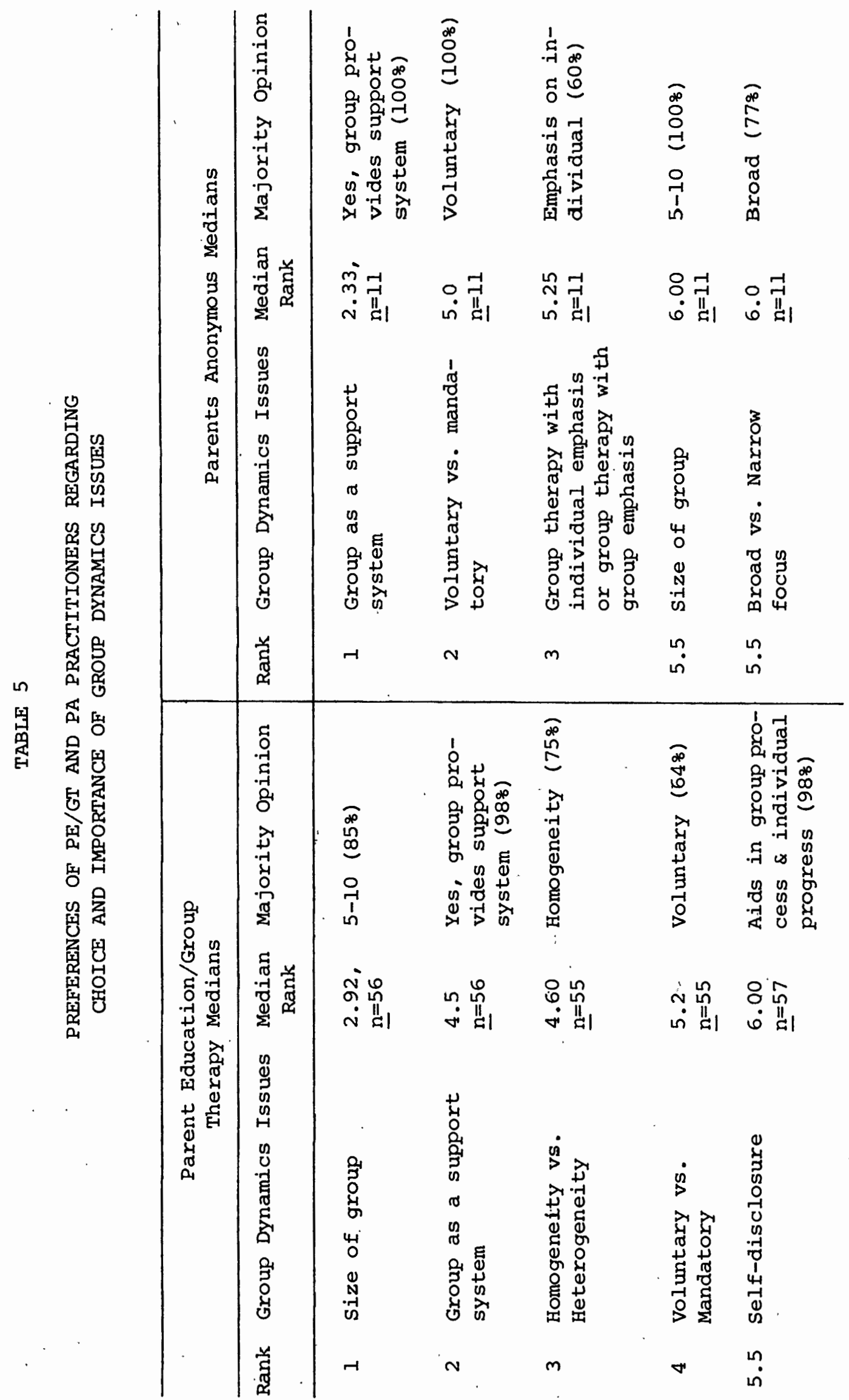




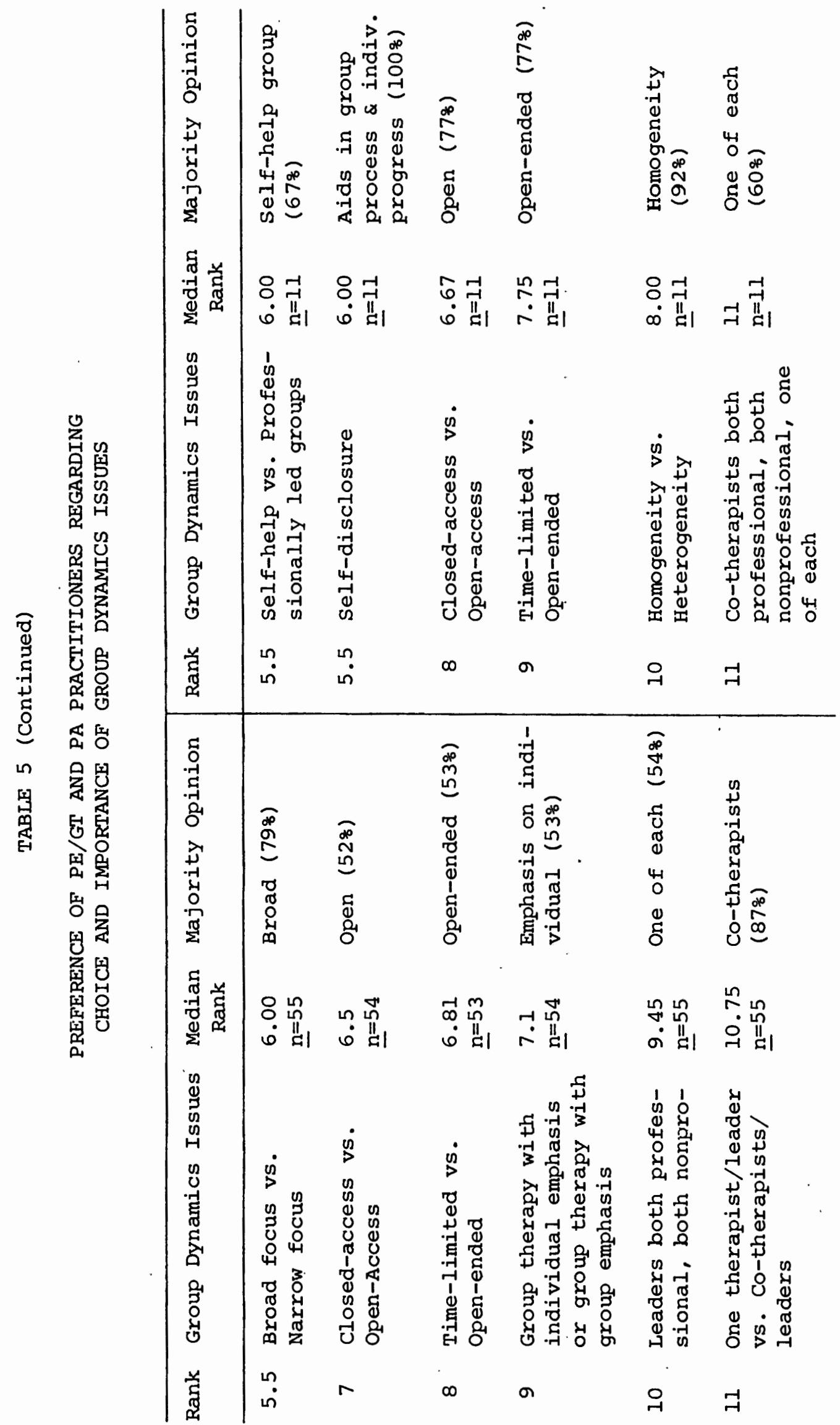




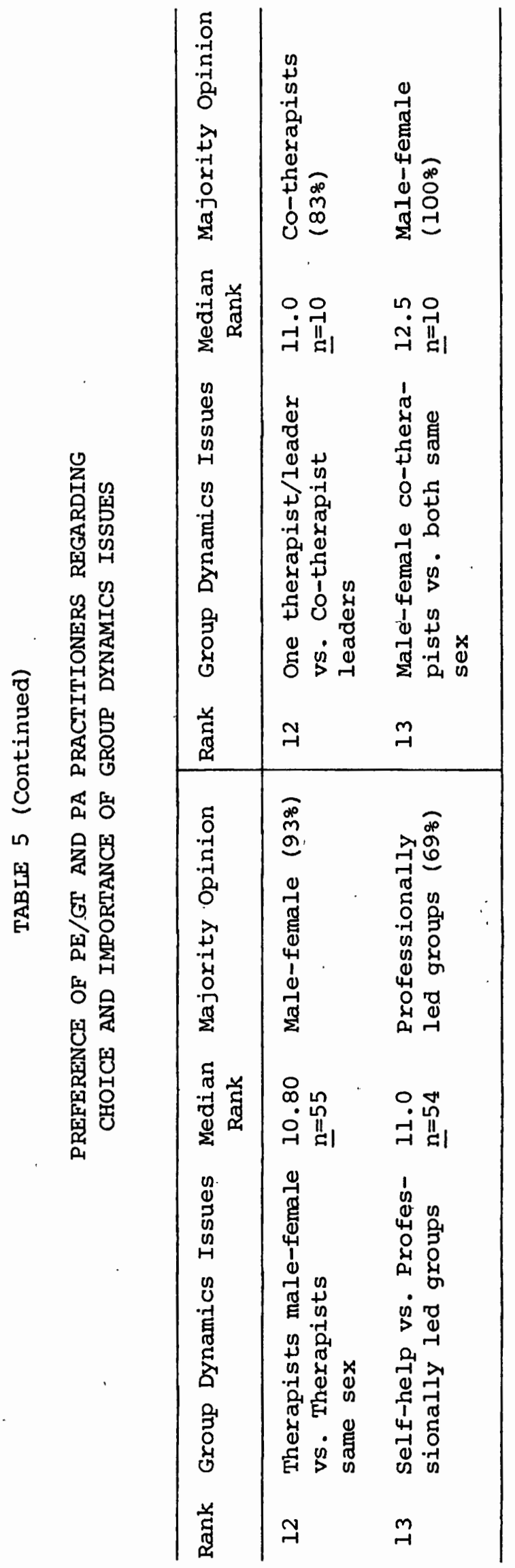


sample. It appears that PA Sponsors prefer self-help groups more than professionally led groups, open-access groups more than closed-access groups, and an open-ended time limit more than the time-limited structure.

The PE/GT practitioners favor professionally led rather than self-help groups, and they are about evenly split on the open-access/closed-access and time-1imited/openended issue.

\section{Theoretical Orientation of Conducting Group Therapy}

Table 6 indicates rankings by the total sample regarding preferred theoretical orientation of conducting group therapy with child abusers. Table 7 indicates rankings by the $\mathrm{PE} / \mathrm{GT}$ sample and $\mathrm{PA}$ sample regarding preferred theoretical orientation of conducting group therapy with child abusers.

Eclectic methods of conducting group therapy received the highest preference ranking by the total sample and for both the PE/GT sample and PA sample.

\section{Parent Education}

Table 8 indicates the ranked effectiveness by the total sample of three possible settings for parent education. Table 9 indicates the ranked effectiveness by the $\mathrm{PE} / \mathrm{GT}$ sample and the PA sample regarding three possible 
TABLE 6

PREFERENCES OF PRACTITIONERS REGARDING

THEORETICAL ORIENTATIONS OF

CONDUCTING GROUP THERAPY

Total Sample Medians
(1) Eclectic $(1.46, \underline{\mathrm{n}}=52)^{\mathrm{a}}$
(2) Behavior modification (2.13, $\underline{\mathrm{n}}=71$ )
(3) Transactional analysis $(2.67, \underline{\mathrm{n}}=70)$
(4) Psychoanalytic (3.18, $\underline{\mathrm{n}}=63)$
(5) Didactic $(3.35, \underline{n}=50)^{a}$

$a_{34}$ and 36 subjects respectively did not rank eclectic and didactic items. Some of this nonresponse appears to be due to the omission of a check line preceding these items. The median rank is therefore based on the ranks of those who did respond.

\section{TABLE 7}

PREFERENCES OF. PE/GT AND PA PRACTITIONERS REGARDING THEORETICAL ORIENTATIONS OF CONDUCTING GROUP THERAPY

Parent Education/Group Therapy Medians

(1) Eclectic (1.5, $\underline{n}=44)$

(2) Behavior modification

$$
(2.10, \underline{n}=60)
$$

(3) Transactional analysis

$$
\text { (2.68, } \underline{n}=59)
$$

(4) Didactic (3.19, $\underline{n}=44)$

(5) Psychoanalytic (3.25, $\underline{n}=54$ )
Parents Anonymous Medians

(1) Eclectic (1.20, $\underline{n}=67)$

(2) Behavior modification

$$
\text { (2.25, } n=11 \text { ) }
$$

(3) Transactional analysis

$$
\text { (2.63, } \underline{n}=11 \text { ) }
$$

(4) Psychoanalytic $(3.13, \underline{n}=9)$

(5) Didactic (3.83, $\underline{n}=6)$ 
TABLE 8

PREFERENCES OF PRACTITIONERS REGARDING SETTINGS FOR CONDUCTING

PARENT EDUCATION

Total Sample Medians
(1) Milieu environment (1.72, $\underline{n}=74)$
(2) Community/social agency $(1.80, \underline{n}=72)$
(3) Hospital $(2.78, \underline{n}=64)$

TABLE 9

PREFERENCES OF PE/GT AND PA PRACTITIONERS REGARDING SETTINGS FOR CONDUCTING

PARENT EDUCATION

$\mathrm{PE} / \mathrm{GT}$

PA

(1) Milieu environment

$$
\text { (1.69, } \underline{n}=72 \text { ) }
$$

(2) Community/social agency

$$
\text { (1.72, } \underline{n}=60 \text { ) }
$$

(3) Hospital

$$
\text { (2.71, } \underline{n}=53 \text { ) }
$$

(1) Milieu environment

$$
\text { (2, } n=11)
$$

(2) Community/social agency

$$
\text { (2.07, } n=12)
$$

(3) Hospital

$$
\text { (3.08, } n=10)
$$

settings for parent education. In all cases, milieu environment (the home of the abusive parent) received the highest rank followed by community/social agency setting. Hospital setting was ranked third.

Table 10 indicates how the total sample ranked theoretical orientations for conducting parent education, from the most preferred to the least preferred orientation. 
TABLE 10

PREFERENCES OF PRACTITIONERS REGARDING THEORETICAL ORIENTATIONS FOR CONDUCTING PARENT EDUCATION

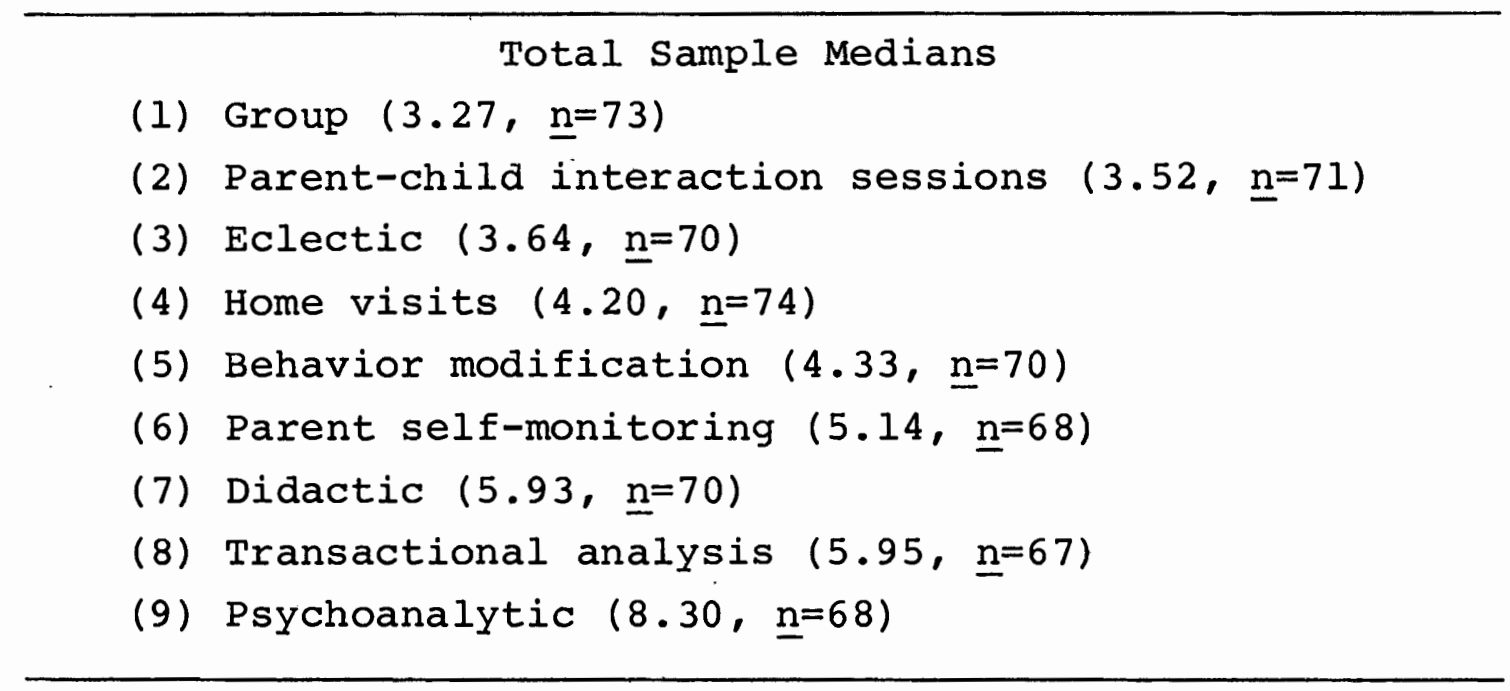

Table 11 indicates how the PE/GT sample and the PA sample ranked preferences of theoretical orientation for conducting parent education.

TABLE 11

PREFERENCES OF PE/GT AND PA PRACTITIONERS REGARDING THEORETICAL ORIENTATIONS FOR CONDUCTING PARENT EDUCATION

Parent Education/Group Therapy Medians

(1.5) Group (3.50, $n=62)$

(1.5) Parent-child interaction sessions $(3.50, n=62)$

(3) Eclectic $(3.70, n=\overline{6} 0)$

(4) Home visits $(4.0 \overline{0}, n=63)$

(5) Behavior mod $(4.10,-n=60)$

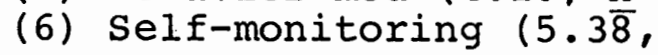
$n=57$ )

(7) Di $\overline{d a c t i c}(5.78, \underline{n}=59)$

(8) Transactional anàlysis $(5.85, n=57)$

(9) Psychoanalytic (8.29, $\underline{n}=57$ )
Parents Anonymous Medians

(1) Group $(2.8, \mathrm{n}=11)$

(2) Eclectic $(3 . \overline{0} 0, n=10)$

(3) Self-monitoring (3.67, $\underline{n}=11$ )

(4) Parent-child interaction sessions ( $3.88, n=11$ )

(5.5) Behavior mod $(5.0, \underline{n}=11)$

(5.5) Home visits $(5.0, n=11)$

(7) Didactic $(6.20, \mathrm{n}=\bar{I} 1)$

(8) Transactional anālysis (6.83, $n=11)$

(9) PsychoanaIytic (8.33, $\underline{n}=11$ ) 
Table 12 indicates the median ranks by the total sample regarding the importance of nine components of parent education. These components appear to combine into three groups of high, moderate, and low importance when ranked by the total sample. Family/parent/child communications, emotional/psychological development, and discipline/setting limits are ranked high in importance by the total sample. Health care, physical development, and sibling rivalry are ranked of moderate importance by the total sample. Feeding, toilet training, and bedtime are ranked of low importance by the total sample.

TABLE 12

PREFERENCES OF PRACTITIONERS REGARDING COMPONENTS OF PARENT EDUCATION

Total Sample Medians

(1) Family/parent/child communications (1.77, $\underline{n}=74$ )

(2) Emotional/psychological development (2.37, $\underline{n}=73$ )

(3) Discipline/setting limits (2.48, $\underline{n}=73$ )

(4) Health care (4.91, $\underline{n}=73$ )

(5) Physical development (5.15, $\underline{n}=64$ )

(6) Sibling rivalry (5.47, $\underline{n}=63)$

(7) Feeding (6.00, $\underline{n}=66)$

(8) Toilet training (7.11, $\underline{n}=65)$

(9) Bedtime $(8.05, \underline{n}=66)$

Table 13 indicates the median ranks by the PE/GT sample and the PA sample regarding the nine components of parent 
education.

One difference between the two groups appeared to be regarding feeding. The $\mathrm{PA}$ sample ranked feeding higher in importance (median rank $=6.00$ ) while the PE/GT sample ranked it lower in importance (median rank $=7.14$ ).

\section{TABLE 13}

PREFERENCES OF PE/GT AND PA PRACTITIONERS REGARDING COMPONENTS OF PARENT EDUCATION

Parent Education/Group Therapy Medians

(1) Family/parent/child communication ( $1.83, \underline{n}=63$ )

(2) Emotional/psychological development $(2.43, \underline{n}=62)$

(3) Discipline, setting limits (2. $48, n=61$ )

(4) Physical development (5.10, $n=58)$

(5) Health care (5.29, $\underline{n}=62)$

(6) Sibling rivalry (5.38, $\underline{n}=56$ )

(7) Toilet training (7.00, $\underline{n}=55)$

(8) Feeding (7.14, $\underline{n}=56)$

(9) Bedtime (7.92, $\underline{n}=56)$
Parents Anonymous Medians

(1) Family/parent/child communication $(1.50, \underline{n}=11)$

(2) Emotional/psychological development $(2.13, \underline{n}=11)$

(3) Discipline/setting limits (2.50, $n=11$ )

(4) Health care $(4.00, \underline{n}=11)$

(5) Physical development (5.10, $\underline{n}=11$ ).

(6) Feeding $(6.00, \underline{n}=10)$

(7) Sibling rivalry (7.00, $\underline{n}=10$ )

(8) Toilet training (7.67, $\underline{n}=10$ )

(9) Bedtime (8.79, $\underline{n}=10)$ 


\section{DISCUSSION}

This discussion section will be organized into the three subsections of child abuse treatment program components, group dynamics issues, and parent education. All sections will interpret the results in light of the literature review.

\section{Child Abuse Treatment Program Components}

Questionnaire results indicated that most questionnaire respondents favored multi-faceted child abuse treatment programs that consist of crisis services, child services, and parent counseling services. For instance, when ranking the treatment components, some interesting combinations occurred. For the total sample, the four highest ranks indicated a tie between a 24-hour hotline (crisis intervention) and individual counseling (counseling services), and another tie between emergency child care (crisis intervention) and family therapy (counseling services).

The PE/GT and PA samples also seemed to favor multifaceted child abuse treatment programs. PE/GT respondents, however, tended to rank child services lower and put more emphasis on crisis and counseling services. Yet since family therapy was ranked higher by the PE/GT sample than 
the PA sample, it could indicate that some PE/GT respondents feel that family therapy is a child service as well as a counseling service (since it involves both children and parents), and that family therapy reduces the need for other child services.

Another difference between the two samples was that PA Sponsors tended to rank peer support network higher than did PE/GT respondents. This could indicate that individuals who feel that peer support in the area of child abuse is very important are those individuals who become PA Sponsors, and also that the PA respondents see the PA self-help groups as a peer support network iteslf.

In summary, the overall rankings of child abuse treatment program components may indicate that respondents feel that stress or crisis situations are indeed involved in child abuse.

\section{Group Dynamics Issues}

Questionnaire respondents ranked six group dynamics issues highest in importance and two issues lowest in importance. While the rankings were either high or low, there was clear agreement by the respondents regarding the favored option. Practitioners who responded to the questionnaire agreed that optimum group size should be 5-10, the group serves as a support system, groups should be homogeneous, group attendance should be voluntary, self-disclosure aids 
in both the group process and individual progress, and broad group focus is preferred as are male-female co-therapists. In the following paragraphs these results will be interpreted. Next, group dynamics issues where there was not a clear consensus will be discussed.

Group size of five to 10 members was preferred by $88 \%$ of respondents. Homogeneous groups were preferred by $78 \%$ of the respondents. These conclusions are supported in the review of the literature in these areas.

$\mathrm{PE} / \mathrm{GT}$ respondents ranked the size of the group as the most important issue, probably indicating that group therapy with abusive parents is difficult and ineffective if done in too large or too small groups. That PA Sponsors ranked the size of the group lower in importance could indicate that the sponsors feel that the group formation is most important and that it can still provide support whatever its size.

As a PA Sponsor, I found that competition among members was decreased if group size remained at less than 10 members. It is my experience that the homogeneous groups offer more support to parents more quickly. Since a characteristic of abusive parents seems to be social isolation and a lack of support, homogeneous groups may be particularly desirable for abusive parents. Also, because of the social and legal ramifications of child abuse, I think that abusive parents need a group with this common identified 
problem for them to feel accepted.

It is clear that respondents saw that a major function of group therapy with abusive parents is to provide a support system for these parents.

I think that the group can serve as a support system no matter what other decisions are made regarding process, leadership, and structure. For this reason, I think it is important for all types of groups to be available for abusive parents, at least until further research determines which groups are most beneficial in treating child abusers. The majority of respondents (70\%) preferred voluntary groups probably because if parents attend voluntarily they have more motivation to change. This does not solve the problem of what to do when parents are mandated to therapy groups. One solution is to group court-ordered parents together. The problem with this, however, could be that these parents would not have a model of parents with more motivation or different coping styles. In any event, it needs to be determined if mandating parents to groups has any effect on their abusive behavior and whether other treatment methods in this situation might be preferable.

As a PA Sponsor, I found mandated parents to be extremely defensive and hesitant to talk when first joining the group. It often took many weeks before parents felt secure within the group. It seemed to me that mandated parents spent more time rationalizing their behavior than 
did parents who came to the group of their own accord. It was more often necessary for the group leaders to confront mandated parents with their behavior. In addition, I noticed that progress in terms of self-disclosure and signs of behavior change were slower for mandated parents. This could be due, however, to some other underlying factor as well as being court-ordered to attend PA.

For reasons of parents' motivation, I would prefer working with voluntary parents. I would be interested, however, in groups which contain only mandated abusive parents. More group research in this area needs to be done, especially as it applies to abusive parents.

Self-disclosure was felt by the overwhelming majority (98\%) to aid individual progress and group process. This result concurs with the findings in the literature review. I think that SD is an important tool for the therapists working with abusive parents and is necessary as a starting point for group members to become involved in the group. When group members self-disclose within the group and still feel accepted by the therapist and their peers, changes in their behavior can begin.

A broad focus was preferred by the majority (798) of all respondents. This could be an indication of the fact that stress and crisis are components of child abuse, and that many factors can enter into an abusive incident. Group therapy for child abusers needs to provide a place for 
recognition and discussion of these factors.

It is my experience that most topics that affect the family can be discussed in groups composed of abusive parents if they are of general concern or educational to other group members. This is particularly true of child management issues. However, special individual concerns or marital counseling regarding a particular couple cannot be done effectively within a group designated for child abusers.

Male-female co-therapists were preferred for group leadership. I feel that co-therapists are important in working with abusive parents. Co-therapists also give flexibility to the group situation, in allowing more experienced therapists to' learn about working with abusive parents and in allowing therapists to play different roles within the group and trade off in these roles if necessary. Since the dependency of many abusive parents is extreme, I prefer co-therapists or co-sponsors in addition to the Chairperson in working in $\mathrm{PA}$ groups.

I also think that having male-female co-therapists is a realistic approach in working with abusive parents. Frequently only mothers attend group sessions and contact with an accepting male can be particularly important.

There was not a clear consensus from questionnaire respondents regarding the group dynamics issues ranked moderate in importance. These issues were open-ended vs. time-limited, open-access vs. closed-access, self-help 
vs. professionally led groups, and group therapy with individual emphasis vs. group therapy with group emphasis. The following elaboration indicates the percentages of respondents making a certain choice.

Open-ended groups were preferred by a slight majority of respondents (57\%). This could reflect the insight by these practitioners that while time-limited groups may be more easily planned and possibly more efficient and effective, open-ended groups allow a solution to the social isolation and dependence of abusive parents.

I think that time-limited groups would make parents focus in more quickly on abuse problems, which is desirable in terms of safety for the children. But, because child abuse carries so many legal and social overtones, it might not be realistic to expect this of abusive parents. It might be necessary for parents to have a great deal of contact with other group members before they are able to deal with their abusive behavior. A slight majority (53\%) of respondents favored open groups, which may reflect that while closed groups can be more effective and efficient, open groups are desirable because of the crisis implication of child abuse.

In fact, this division becomes more apparent when comparing the two samples. The majority (77\%) of PA respondents preferred open groups as supported by their organization while a slight majority (52\%) of the PE/Gr 
respondents preferred closed groups. This could be due to the mechanics involved in the work situations for $\mathrm{PE} / \mathrm{GT}$ respondents. Closed groups provide more structure in a work setting and allow for financial planning.

I think that in working with abusive parents, the main problem of closed groups is their inaccessibility to parents who are in crisis. The main problem with open groups is the fluid membership. It is possible to have several new members attend a meeting one week and have only three or four participants the next.

A narrow majority (54\%) of all respondents favored therapy with emphasis on the individual. Perhaps this shows that questionnaire respondents are aware that while it is the individual who needs to come to terms with and change his or her abusive behavior, the group can facilitate this change.

I think that a middle ground is possible and desirable with abusive parents in group situations leading to individual analysis of dealing with issues brought up in the group. Initially I. feel it is important to emphasize the group process to new members, since this is less threatening. As members feel more secure, I would move towards an individual emphasis using the group for feedback and support.

From the questionnaire results, it is clear that while male-female co-therapists were preferred by the majority (94\%) of the total sample, at least one of these therapists 
should be a professional, according to $54 \%$ of the respondents. Of the total respondents, 448 preferred both leaders to be professional. Of the PA respondents, $60 \%$ preferred co-therapists, one of whom is professional and one of whom is not, in keeping with the self-help model.

I think that having a parent-model in the group as described by the Extended Family Center encourages selfdisclosure by other members. However, it is unrealistic to expect most PA Chairpeople to assume direction of the group and be aware of group process. I think it is necessary for many sponsors to direct the group, particularly in the interpretation of behavior. Chairpeople can learn how to encourage parents to give background information, but they may not be able to do this initially.

While self-help groups have the advantage of appearing less threatening and having a lower profile, they might not resolve situations as quickly due to inexperience of the leaders, so while modeling behaviors and attitudes can be expressed by a self-help leader, interpretation and group process can be handled more adequately by a professional. The issue of screening parents was not included in the ranking of group dynamics issues. However, 718 of the total respondents were in favor of screening parents. of the PA respondents, $62 \%$ favored screening and of the PE/GT respondents $73 \%$ favored screening.

While screening procedures for the PE/GT programs and 
Total Treatment Programs were not described in detail in the available literature, PA specifically does not favor screening parents. However, the majority of all respondents, including PA Sponsors, preferred screening parents, probably for the reasons explored in the literature review: that some individuals cannot participate in group therapy and may be destructive to the group.

I think that there are some individuals who are not ready for group therapy in terms of verbal skills and some individuals who are very dependent and perhaps need another sort of treatment initially. Other people can be so hostile, aggressive, or manipulative that they are destructive to the group. All of these people need to be screened out. In the PA situation, it is necessary for the group leaders to judge if parents are capable of group participation and, if not, to direct these individuals to the appropriate treatment settings.

\section{Parent Education}

Questionnaire respondents ranked a milieu setting highest for conducting parent education. This could indicate that respondents feel that parent education can best be done in a less clinical setting. A milieu environment, whether it is the home of the abusive parent or a treatment milieu such as Circle House, has the advantage of allowing staff observation of parent interaction with the child, and 
parent observation of professionals' interaction with the child, as well as more formal teaching techniques. In fact, the staff members of Circle House and the Extended Family Center indicate that one of the benefits of these programs is that they provide a setting where parents can be observed and where parents can also learn from watching staff involvement with their children.

In ranking theoretical orientations of conducting parent education, group methods was ranked first by respondents, followed by parent-child interaction sessions. Both methods were rated as extremely effective ways of conducting parent education with child abusers. The high ranking of group methods might indicate that while respondents feel parent education is necessary, it can be effectively combined with the support system provided in groups. While it is not known if parent education can prevent child abuse or discontinue it, it seems logical that if parents learn appropriate ways of communicating with and disciplining their children as well as development patterns of children, they are better equipped to be parents.

Responses regarding components of parent education seemed to indicate that abusive parents need information regarding family communication and how to set limits for their children. Also parents need to learn about psychological and physical child development as well as health care.

I also think that parents need education regarding 
family communication and information regarding appropriate discipline. But part of the education in these areas is necessary because abusive parents have unrealistic expectations of their children. I think that they lack knowledge of normal child development. This lack of knowledge can create abuse incidents when parents expect behavior that is not possible for a child. A major part of parent education should be clarifying child development for abusive parents so they will have realistic expectations of their children. Then, specific parent skills regarding communication and setting limits can be taught in light of what is appropriate to expect of a child at a particular age and in a particular situation. 


\title{
CONCLUSIONS AND RECOMMENDATIONS
}

Table 14 summarizes the guidelines for treatment with child abusers outlined in this section. An elaboration of these conclusions and recommendations follows.

\author{
TABLE 14
}

GUIDELINES FOR TREATMENT

WITH CHILD ABUSERS

I. Stress or crisis seems to be associated with child abuse.

A. Emergency services to help parents in crises are:

1. 24-hour hotline

2. 24-hour on-call staff

3. Emergency child care

II. Abusive parents seem to lack information regarding parent skills, and child care. They need education regarding :

1. Family communication

2. Emotional/psychological child development

3. Discipline/Setting limits

4. Health care

5. Physical child development

III.Abusive parents seem to be socially isolated. Groups for child abusers may be effective in providing a 
TABLE 14 (Continued)

support system. There can be two types of groups:

A. Support or crisis groups open to any parent in need of support or referral.

B. Therapy groups which, while also providing support, concentrate on group treatment to alleviate abuse. These groups seem to be effective if the following guidelines are observed:

1. Parents are screened before group attendance.

2. Groups are homogeneous and child abuse is the identified problem.

3. Group size is limited to ten people.

4. Groups have a formerly abusive parent to serve as a model for changing abusive behavior.

5. Groups have male-female co-therapists.

The questionnaire reports opinions of individuals working with child abusers. Their overall responses indicate that there is a stress or crisis component to the problem of child abuse and that treatment offerings need to take this into account.

Also, respondents were $100 \%$ in favor of parent education and felt that it should be included in a child abuse treatment program. Respondents preferred group methods when conducting parent education. This education should include information about family communication, emotional/ 
psychological development of the child, discipline/setting limits, health care, and physical development of the child. From questionnaire responses it could also seem that respondents think that a part of child abuse is due to uneducated parents. Previous research supports the fact that many abusive parents have unrealistic expectations of their children given a child's age and development (Burglass, 1971; Delivossovoy, 1973; Johnson \& H. Morse, 1968; C. Morse, 1970). Therefore, parent education should be a top priority of child abuse treatment programs. It can then be determined if abusive parents who receive parent education improve more than abusive parents who do not receive it. This could be researched specifically by assigning parents who attend another treatment component such as individual therapy to one of two groups. One group would receive parent education and the other would not. Going one step further, parents could also be randomly assigned to parent education in a variety of settings to see if one setting, such as a home setting, is more beneficial as indicated by the questionnaire respondents. Parent education could also be conducted according to different methods to determine if one works better with abusive parents. Parent education needs to be available for abusive parents and these studies could determine how it would be most effective.

In the area of group therapy, the results indicated 
that the group serves as a support system for abusive parents. Group size should be between five and 10 members, groups should be homogeneous, and parents should be screened before participating in groups. These factors should be considered when beginning groups for abusive parents.

Other group dynamic issues were less straightforward. There should be detailed reports regarding the group structure, leadership, and group process of group therapy now being done with abusive parents. It needs to be determined what group dynamics issues are important when working with abusive parents. For example, do parents improve faster if group therapy is time-limited? Does screening out certain parents increase the group's support system and make it more cohesive? Do mandated parents really respond differently than voluntary ones? If so, how?

Since many groups are now open-access and open-ended, it might be assumed that they are better for abusive parents even if this is not the case. Perhaps two levels of group therapy could be used with child abusers, one as a basic support system, always available--especially for those in crisis--and one geared more toward resolving abuse problems and educating parents. Again, more research is needed regarding groups, their structure, process, and effectiveness, and how effective groups are with child abusers.

Parents Anonymous, using a self-help group model, has had a tendency in the past to emphasize that while other 
group methods or treatment options can be and are used with abusive parents, to include them in PA is inappropriate (Parents Anonymous Chairperson/Sponsor Manual, 1975). Perhaps the time has come for this organization to re-think this policy. As a national organization providing help to thousands of abusive parents, it is important for PA to recognize that while groups, self-help or not, are very important to abusive parents, there are indications in the field and in research that PA policy changes may need to occur.

One such change is screening parents before admittance to groups. There is sufficient evidence to indicate that this is desirable. Admittedly, it might make PA groups less "open," but, on the other hand, some PA groups may not be effective because of this lack of screening.

Also, it could be that PA needs to put more emphasis on the fact that PA alone might not be enough in terms of treatment for abusive parents. Therefore, detailed policies for making referrals for other types of treatment should be developed.

Another area for change could be including parent education within PA. Questionnaire responses indicated a preference for parent education done in groups and PA, since it is already well established in many communities, could assume this role. Often it is not realistic to expect Chairpeople who have the ability to be good models and 
handle group process to be available to all PA chapters. There might need to be more flexibility regarding sponsor involvement in the group so that the group is effective even if a Chairperson is not available. Also, if parent education was included in meetings, the sponsor would be the qualified person to conduct it and also to judge if parents needed other types of treatment. It might be necessary to increase the qualifications of sponsors to insure that they have experience in child development, psychological funtioning, and group process. Studies could be conducted to determine if PA groups with more qualified sponsors are more effective.

PA organizations could also take advantage of the parents' meeting time to offer therapeutic alternatives for the children.

Naturally, these changes might be difficult to carry out; however, the benefits might warrant making them.

In this particular study, there were several problems. One is that while the listings in the Child Abuse and Neglect Program manual stated that certain programs had parent education and/or group therapy or Parents Anonymous, there were a sizable number of programs which indicated in the follow-up that they no longer had these services. This could indicate a change of focus within these programs or also that there is a great deal of instability within child abuse programs. 
One problem related to the literature review and subsequent design of the questionnaire was the lack of available literature regarding treatment programs in the area of child abuse and neglect. Programs that were described often lacked specific detail regarding treatment as well. Also, most reports were based on clinical observations alone.

Another problem regarded the use of the child Abuse and Neglect Program manual to obtain samples. Program descriptions in the manual often indicated that "counseling services" were offered, but with no indication of which counseling services these were. Since the sample was based on programs that offered group therapy, parent education, or Parents Anonymous, the sample is biased towards those programs which listed specific counseling services in their program descriptions. More uniformity regarding detailed program descriptions could aid other researchers.

With hindsight, I would make the questionnaire shorter. There were several comments regarding the length made by questionnaire respondents and this could be one reason why more questionnaires were not returned. The questionnaire could be shortened by only including the ranking question for the child abuse treatment program components and not asking if they should be included or how important they are. of course, there are many problems in conducting research in the field of child abuse and neglect. It is 
difficult to use control groups and to select random samples. In the area of treatment, moral considerations become paramount as children's welfare is at stake. It has been suggested that experimental design may have to be sacrificed due to moral and practical considerations and the laws regarding informed consent and human experimentation (Innovative Treatment Approaches to Child Abuse and Neglect, 1977).

More research needs to be done in the treatment area of child abuse and neglect despite the methodological problems in doing it. This survey is intended as a starting point for further research regarding child abuse treatment program components, and parent education and group therapy for abusive parents. It is also intended for use by those setting up child abuse treatment programs and conducting group therapy and parent education with child abusers. 
REFERENCES

Alexander, H. M., \& Rodenheffer, M. Residential family therapy. In $\mathrm{H}$. Martin (Ed.), The abused child: A multidisciplinary approach to developmental issues and treatment. Cambridge, Mass.: Bollinger Publishers, 1976.

Allen, J. C. Implications of research in self-disclosure for group psychotherapy. International Journal of Group Psychotherapy, 1973, 23, 306-321.

Bean, S. I. The Parents' Center Project: A multiservice approach to the prevention of child abuse. Child Welfare, 1971, 50(5), 277-282.

Bean, S. I. Use of specialized day care in preventing child abuse. In Child abuse: Intervention and treatment. Acton, Mass.: Publishing Sciences Group- Inc., 1975.

Belluci, M. T. Group treatment of mothers in child protection cases. Child Welfare, 1972, 51(2), 110-116.

Bion, W. R. Experiences in groups. London: Tavistock, 1961.

Brem, J. Child abuse control centers: A project for the academy. Pediatrics, $1970, \underline{45}(5), 894-895$.

Bremmer, I. M., \& Shostrom, E. I. Therapeutic psychology. Englewood Cliffs, N.J.: Prentice-Hall, Inc., 1968.

Brown, J.A., \& Daniels, R. Some observations on abusive parents. Child Welfare, 1968, $47(2), 89-94$.

Buchanan, F. Theme-centered, time-limited group therapy. In $\mathrm{H}$. Rutenbeek (Ed.), Group therapy today. New York: Atherton Press, Inc., $1 \overline{969 .}$

Buglass, R. Parents with emotional problems. Nursing Times, 1971, 67, 1000-1001.

Cartwright, D., and Iippitt, R. Group dynamics and the individual. In W. G. Bennis, $K$. O. Benne, \& R. Chin (Eds.), The planning of change. New York: Holt, Rinehart \& Winston, 1961. 
Child abuse and neglect programs. U.S. Department of HEW, Office of Human Development Services, Administration for Children, Youth and Families, U.S. Children's Bureau, National Center on Child Abuse and Neglect, March, 1978.

Child abuse, and neglect reports, June 1976. National Center on Child Abuse and Neglect, U.S. Department of HEW.

Cohn, A. H., Ridge, S. S., \& Collignon, F. C. Evaluating innovative treatment programs in child abuse and neglect. Children Today, 1970, 49(9), 486-494.

Coleman, W. Occupational therapy and child abuse. American Journal of Occupational Therapy, 1975, 29(7).

Collins, B., \& Guetzkow, H. A social psychology of group processes for decision making. New York: John Wiley \& Sons, Inc., 1964.

Committee on group treatment in family service agencies. Sherman, Sanford N., Chairman. Family Service Association of America, 1964.

Delissovoy, V. Child care by adolescent parents. Children Today, $1973, \underline{2}(4), 22-25$.

Elmer, E. Child abuse: The family's cry for help. Journal of Psychiatric Nursing, 1967, $\underline{5}(4), 332-341$.

Fontana, V. J. Which parents abuse children? Medical Insight, 1971, $3(10), 16-21$.

Fried, E. Comprehensive group psychotherapy. In H. I. Kaplan, \& B. J. Sadock (Eds.), Comprehensive group psychotherapy. Baltimore: Williams \& Wilkins Co., 1971.

Friedman, R. M. Child abuse: A review of the psychosocial research. Four perspectives on the status of child abuse and neglect research. Washington, D.C.: HEW, National Center on Child Abuse and Neglect, Children's Bureau, Office of Child Development, 1976.

Galdston, R. Violence begins at home: The Parents' Center Project for the study and prevention of child abuse. Journal of American Academy of Child Psychiatry, 1971, $10,336-350$.

Galdston, R. Preventing the abuse of little children: The Parents' Center Project for the study and prevention of child abuse. American Journal of Orthopsychiatry, $1975, \underline{45}(3), 372-381$. 
Gelles, R. J. The violent home: A study of physical aggression between husbands and wives. Beverly Hills, Calif.: Sage Publication, 1972 .

Gelles, R. J. Child abuse as psychopathology: A sociological critique and reformulation. American Journal of Orthopsychiatry, 1973, 43(4), 611-621.

Gelles, R. J. Etiology of violence: Overcoming fallacious reasoning in understanding family violence and child abuse. Child abuse - where do we go from here? Conference Proceedings February 18-20, 1977. Washington, D.C.: Child Protection Center, Children's Hospital, National Medical Center.

Gil, D. G. Violence against children: Physical child abuse in the United States. Cambridge, Mass.: Harvard University Press, 1970 .

Gil, D. G. Violence against children. Journal of Marriage and Family, November, 1971, 644-648.

Goldberg, C., \& Goldberg, M. C. The human circle. Chicago: Nelson-Hall Co., 1973.

Goldstein, A., \& Wolpe, J. Behavior therapy in groups. In H. I. Kaplan \& B. J. Sadock (Eds.), New models for group therapy. New York: Dutton, $19 \overline{72 .}$

Hartford, M. E. Groups in social work. New York: Columbia University Press, 1971.

Heath, E. S., \& Bocal, H. A. A method of group psychotherapy at the Tavistock Clinic. In Progress in group and family therapy. New York: Brunner/Mazel, 1972.

Helfer, R. A plan for protection: The child abuse center. Child Welfare, 1970, $49(9), 486-494$.

Helfer, R. E. Medical aspects of child abuse and neglect: A review of the research literature. Four perspectives on the status of child abuse and neglect research. Washington, D.C.: HEW, National Center on Child Abuse and Neglect, Children's Bureau, Office of Child Deve1opment, 1976.1

Helfer, R., \& Kempe, C. H. (Eds.). Child abuse and neglect: The family and the community. Cambridge, Mass.: Ballinger, 1976. 
Hobbs, N. Group centered psychotherapy. In C. R. Rogers (Ed.), Client-centered therapy. Boston: Houghton, 1951 .

Homemaker Service of the National Capital Area, Inc. Strengthening family life through homemaker home health aide services: A report of a special project conducted in Washington, D.C., 1971 .

Innovative treatment approaches for child abuse and neglect. Washington, D.C.: National Center of Child Abuse and Neglect, June 1977.

Johnson, B., \& Morse, H. A. Injured children and their parents. Children, 1968, 15(4), 147-152.

Johnston, C. Parental stress service - how it all began. Journal of Clinical Child Psychology, 1973, 2 (3), 45.

Kadis, A., Krasner, J. O., Winick, C., \& Foulkes, S. H. A practicum of group psychotheraphy. New York: Harper \& Row, 1965.

Katz, S. N., Ambrosino, L., McGrath, M. , \& Sawitsky, K. The laws on child abuse and neglect. Four perspectives on the status of child abuse and neglect research. Washington, D.C.: HEW, National Center on Child Abuse and Neglect, Children's Bureau, Office of Child Development, 1976 .

Kempe, C. H. A practical approach to the protection of the abused child and the rehabilitation of the abusing parent. Pediatrics, 1973, 51, 804-812.

Lazarus, A. A. Behavior therapy in groups. In G. M. Gazda (Ed.), Basic approaches to group psychotherapy and group counseling. Springfield, I1l.: Charles $C$. Thomas, 1968 .

Lieber, L. A new direction against child abuse. In S. B. Harris (Ed.), Child abuse: Present and future. Chicago: National Committee for Prevention of child Abuse, 1975.

Lubin, B. Group therapy. In I. B. Weiner (Ed.), Clinical methods in psychology. New York: John Wiley \& Sons, 1976 .

Melnick, B., \& Hurley, J. R. Distinctive personality attributes of child-abusing mothers. Journal of Consulting Clinical Psychology, 1969, 33, 746-749. 
Multidisciplinary teams in child abuse and neglect programs. Washington, D.C.: HEW, National Center on Child Abuse and Neglect, U.S. Children's Bureau, 1978.

Newberger, E. H., Reed, R. B., Daniel, J. H., Hyde, J. N., \& Kotelchuck, M. Toward an etiological classification of pediatric social illness: A descriptive epidemiology of child abuse and neglect, failure to thrive, accidents, and poisonings in children under four years of age. Paper presented at the biennial meeting of the Society for Research on Child Development, Denver, 1975.

Parents Anonymous Chairperson - Sponsor Manual, Redondo Beach, Calif.: Parents Anonymous, 1975.

Parke, R. D., \& Collmer, C. W. Child abuse: An interdisciplinary analysis. Chicago: University of Chicago Press, 1975.

Patterson, G. R., \& Gullion, M. E. Living with children: New methods for parents and teachers (Rev. ed.). Champaign, Ill.: Research Press, 1974 .

Paulson, M. J., \& Blake, P. R. The physically abused child: A focus on prevention. Child Welfare, 1969, 48, 86-95.

Paulson, M. J., \& Chaleff, A. Parent surrogate roles: A dynamic concept in understanding and treating abusive parents. Journal of Clinical Child Psychology, 1973, $\underline{2}(3), 43-4 \overline{4}$.

Paulson, M. J., Chaleff, A. G., \& Frisch, F. Parents of the battered child: A multidisciplinary group therapy approach to life-threatening behavior. Life Threatening Behavior, $1974, \underline{4}(1), 13,31$.

Pike, E. L. A timely experiment in the prevention of child abuse. Journal of Clinical Child Psychology, 1.973, $\underline{2}(3), 43-44$.

Planning and implementing child abuse and neglect service programs. Washington, D.C.: HEW, National Center on Child Abuse and Neglect, Children's Bureau, Office of Child Development, 1971.

Polansky, N. A. Child neglect: Understanding and reaching parents. New York: Child Welfare League of America, 1973 .

Polansky, N. A., Hully, C., \& Polansky, N. F. Profile of neglect: A survey of the state of knowledge of child neglect. Washington, D.C.: HEW, Office of Human Development Services/Administration for Public Services. 
Powdermaker, F. B., \& Frank, J. D. Group psychotherapy: Studies in methodology of research and therapy. Cambridge, Mass.: Harvard University Press, 1953.

Qavner, P. Mothers anonymous: The last resort. In J. E. Leavitt (Ed.), The battered child: Selected readings. Morristown, N.J.: General Learning Corp., 1974 .

Savino, A. B., \& Sanders, R. W. Working with abusive parents, group therapy and home visits. American Journal of Nursing, 1973, 73, 482-484.

Slaby, D. Program description and progress report: Children's day school and parent training programs.

Seattle: Department of Behavioral Sciences, Children's Orthopedic Hospital, June 1974.

Slavson, S. R. A textbook in analytic group psychotherapy. New York: International Universities Press, 1964.

Smith, R. C. New ways to help battering parents. Today's Health, 1973, 5l, 57-64.

Spinetta, J. J., \& Rigler, D. The child-abusing parent: A psychological review. Psychological Bulletin, 1972, 77(4), 296-304.

Steele, B. F. Working with abusive parents from a psychiatric point of view. Washington, D.C.: HEW, 1975.

Steele, B. F., \& Pollock, C. B. A psychiatric study of parents who abuse infants and small children. In R. E. Helfer \& C. H. Kempe (Eds.), The battered child. Chicago: University of Chicago Press, 1968.

TenBroeck, E. The Extended Family Center. Children Today, $1974, \underline{3}(2), 2-6$.

Tracy, J. J. Treatment for child abusers. Social Work, $1974, \underline{19}(3), 338-342$.

Walters, D. Physical and sexual abuse of children. Bloomington: Indiana University Press, 1975.

Whitaker, P. S., \& Iieberman, M. A. Psychotherapy through the group process. New York: Atherton Press, 1964.

Wolf, A. Psychoanalysis in groups. In G. M. Gazda (Ed.), Basic approaches to group psychotherapy and group counseling. Springfield, Ill.: Charles C. Thomas. 
Yalom, I. D. The theory and practice of group psychotherapy. New York: Basic Books, 1970.

Young, L. Wednesday's children: A study of child neglect and abuse. New York: McGraw-Hill, 1964. 
APPENDIX A

QUESTIONNAIRE COVER LETTER

September, 1978

\section{Dear Program Director:}

I am working on a Master's degree in psychology at Portland state University. I have completed the required course work and am now engaged in writing a thesis in the area of child abuse. More specifically, I am concerned with group therapy for abusive parents and parent education/ child management classes for them.

The enclosed questionnaire asks for opinions on services offered to abusive parents, group therapy issues and parent education/child management class techniques.

The questionnaire is based on my own experience as a Parents Anonymous sponsor and on published articles regarding group therapy and/or parent education/child management classes for child abusers.

This questionnaire is being sent to a sample of programs listed in the March, 1978 Child Abuse and Neglect Programs guide and questionnaire results will be included in my thesis.

The questionnaire should be filled out by the therapist who has had the most experience in doing group therapy with abusive parents. If no group therapy is offered in your program, but parent education classes are offered, the most experienced instructor of these classes should fill out the questionnaire.

If both group therapy and parent education are offered in your program, the most experienced group therapists should fill out the questionnaire. The questionnaire should be returned in the enclosed envelope.

The thesis as a whole will first describe "ideal" programs for abusive parents and their children. Then characteristics of child abusers will be outlined followed by a discussion of group dynamic issues and how they are related to working with child abusers. The need for parent education will be discussed, and then, documented programs that use group therapy and/or parent education will be detailed bringing out the issues that the therapists in these programs feel are important when using these techniques with abusive parents.

With the data gathered from the questionnaire, the thesis will expand on the group therapy and parent education issues brought out in the program descriptions and the questionnaire results will be summarized. The thesis, when completed, will be a guide for research and practice in working with abusive parents, with special emphasis in the areas of parent education and group therapy, and is intended for practitioners. 
September, 1978

Page 2

Your participation, then, will help those working with child abusers learn what to consider when conducting group therapy and parent education, or when planning research in this area.

Hopefully, the thesis will be available to psychologists, social workers and protective service workers involved in the area of child abuse.

I appreciate your assistance and the time involved in completing the questionnaire.

Sincerely,

Jane Crawford

(To be filled out by questionnaire respondent--PLEASE CHECK)

Our Program offers the following services for abusive parents:

Therapeutic daycare

24-hour hotline

Emergency child care

Group therapy

Family therapy

Information referral

Peer support network

Parent education/child management

classes
Daycare

24-hour on-call staff Individual counseling Self-help group Marital counseling Parent advocacy Home visits

I conduct group therapy with abusive parents

I conduct parent education classes with abusive parents

I conduct a self-help group or am a Parents Anonymous Sponsor

I would like a copy of the thesis abstract 


\section{APPENDIX B \\ CHILD ABUSE TREATMENT PROGRAM QUESTIONNAIRE \\ AND FREQUENCY DISTRIBUTIONS}

"Model" child abuse treatment programs include many types of services for both the abused children and abusive parents. This first group of questions asks for your opinions regarding these components of a child abuse treatment program: daycare, therapeutic daycare, 24-hour hotline, information referral, parent advocacy program, peer support network, 24-hour on-call staff members, individual counseling, marital counseling, family therapy, and group therapy. Please circle your response.

1. Should daycare be included in a child abuse treatment program?

1

Yes

81

67

14
2

No

Total sample $(\underline{n}=83)$

$\mathrm{PE} / \mathrm{GT} \quad(\mathrm{n}=69)$

$\mathrm{PA}(\underline{\mathrm{n}}=\bar{l} \overline{4})$
2

2

0

2. How important is daycare as a component of this kind of program?

$\begin{array}{llllll}1 & 2 & 3 & 4 & 5\end{array}$

Extremely Moderately Slightly Not at all Actually

Important Important Important Important Harmful

\begin{tabular}{|c|c|c|c|c|c|}
\hline Total sample $(n=83)$ & 47 & 29 & 7 & 0 & 0 \\
\hline$P E / G T \quad(n=69)$ & 36 & 26 & 7 & 0 & 0 \\
\hline $\mathrm{PA} \quad(\underline{n}=1 \overline{4})$ & 11 & 3 & 0 & 0 & o \\
\hline
\end{tabular}

3. Should therapeutic daycare where abused children receive therapy along with daily supervision be included in a child abuse treatment program?

12

Yes No

Total sample $(\underline{n}=83) \quad 82 \quad 1$

$\mathrm{PE} / \mathrm{GT}(\mathrm{n}=68) \quad 63 \quad 4$

$\mathrm{PA}(\underline{n}=1 \overline{4}) \quad 14 \quad 0$


APPENDIX B (Continued)

4. How important is therapeutic daycare as a component of this kind of program?

$$
\text { 1. } 20345
$$

Extremely Moderately slightly Not at all Actually Important Important Important Important Harmful

$\begin{array}{lrrlll}\text { Total sample }(\underline{n}=82) & 37 & 37 & 8 & 0 & 0 \\ \text { PE/GT }(n=68) & 30 & 32 & 6 & 0 & 0 \\ \text { PA }(\underline{n}=1 \overline{4}) & 7 & 5 & 2 & 0 & 0\end{array}$

5. Should emergency child care (crisis nursery) be included in a child abuse treatment program?

12

Yes No

Total sample $(\underline{n}=83) \quad 82 \quad 1$

$\mathrm{PE} / \mathrm{GT}(\mathrm{n}=69) \quad 69 \quad 0$

$\mathrm{PA}(\underline{n}=1 \overline{4}) \quad 13 \quad 1$

6. How important is emergency child care as a component of this kind of program?

$1^{\vdots} \quad 2 \quad 3 \quad 4 \quad 5$

Extremely Moderately slightly Not at all Actually Important Important Important Important Harmful

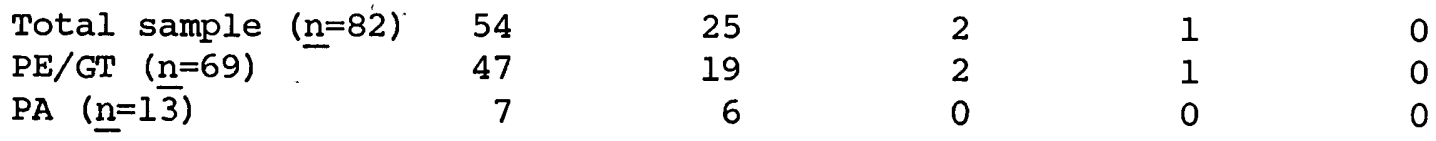

7. Should a 24-hour hotline be included in a child abuse treatment program?

12

Total sample $(\underline{n}=83) \quad 81 \quad 2$

$\mathrm{PE} / \mathrm{GT}(\mathrm{n}=69) \quad 68 \quad 1$

$\mathrm{PA}(\underline{\mathrm{n}}=1 \overline{4}) \quad 13 \quad 1$

8. How important is a 24 -hour hotline as a component of this kind of program?

$12 \quad 3 \quad 4 \quad 5$

Extremely Moderately slightly Not at all Actually

Important Important Important Important Harmful

Total sample $(\underline{n}=84) \quad 62$

$\mathrm{PE} / \mathrm{GT} \quad(\underline{n}=70)$

PA $(n=1 \overline{4})$
51

11
14

13

1
7

5

2
1

1

0
0

0

0 
APPENDIX B (Continued)

9. Should information referral for psychological counseling, welfare, food stamps and so on be included in a child abuse treatment program?

1

Yes

82

68

14

2

No

Total sample $(\underline{n}=84)$

$\mathrm{PE} / \mathrm{GT} \quad(\underline{n}=70)$

PA $(\underline{n}=1 \overline{4})$

10. How important is information referral as a component of this kind of program?

$$
1
$$

2

3

4

5

Extremely Moderately Slightiy Not at all Actually Important Important Important Important Harmful

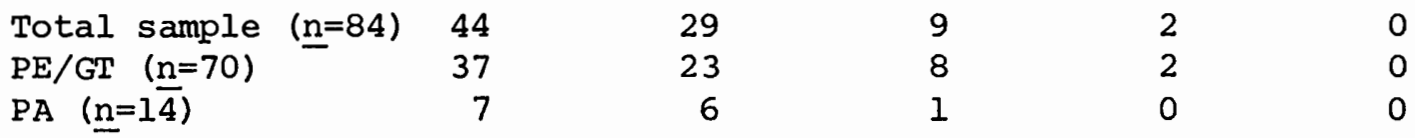

11. Should a parent advocacy program which would provide advocates to accompany parents to court hearings, welfare offices and so on be included in a child abuse treatment program?

$\begin{array}{rr}1 & 2 \\ \text { Yes } & \text { No } \\ 71 & 13 \\ 58 & 12 \\ 13 & 1\end{array}$

12. How important is a parent advocacy program in this kind of program?

$$
\begin{array}{lllll}
1 & 2 & 3 & 4 & 5
\end{array}
$$

Extremely Moderately Slightly Not at all Actually Important Important Important Important Harmful

$\begin{array}{lrrrrr}\text { Total sample }(\underline{n}=81) & 23 & 34 & 15 & 7 & 2 \\ \mathrm{PE} / \mathrm{GT}(\mathrm{n}=67) & 18 & 28 & 13 & 7 & 1 \\ \mathrm{PA}(\underline{n}=1 \overline{4}) & 5 & 6 & 2 & 0 & 1\end{array}$

13. Should a peer support network which would provide contacts for parents with other abusive parents be included in a child abuse treatment program?

$\begin{array}{lrr} & 1 & 2 \\ & \text { Yes } & \text { No } \\ \text { Total sample }(\underline{n}=84) & 82 & 2 \\ \text { PE/GT }(n=70) & 68 & 2 \\ \text { PA }(\underline{n}=1 \overline{4}) & 14 & 0\end{array}$




\section{APPENDIX B (Continued)}

14. How important is a peer support network in this kind of program?

$$
\begin{array}{lllll}
1 & 2 & 3 & 4 & 5
\end{array}
$$

Extremely Moderately Slightly Not at all Actually

Important Important Important Important Harmful.

\begin{tabular}{|c|c|c|c|c|}
\hline al sample & 44 & 24 & 15 & 0 \\
\hline $\mathrm{PE} / \mathrm{GT} \quad(\mathrm{n}=69)$ & 34 & 23 & 12 & 0 \\
\hline $\mathrm{PA} \quad(n=1 \overline{4})$ & 10 & 1 & 3 & 0 \\
\hline
\end{tabular}

15. Should a 24-hour on-call staff member be provided in a child abuse treatment program?

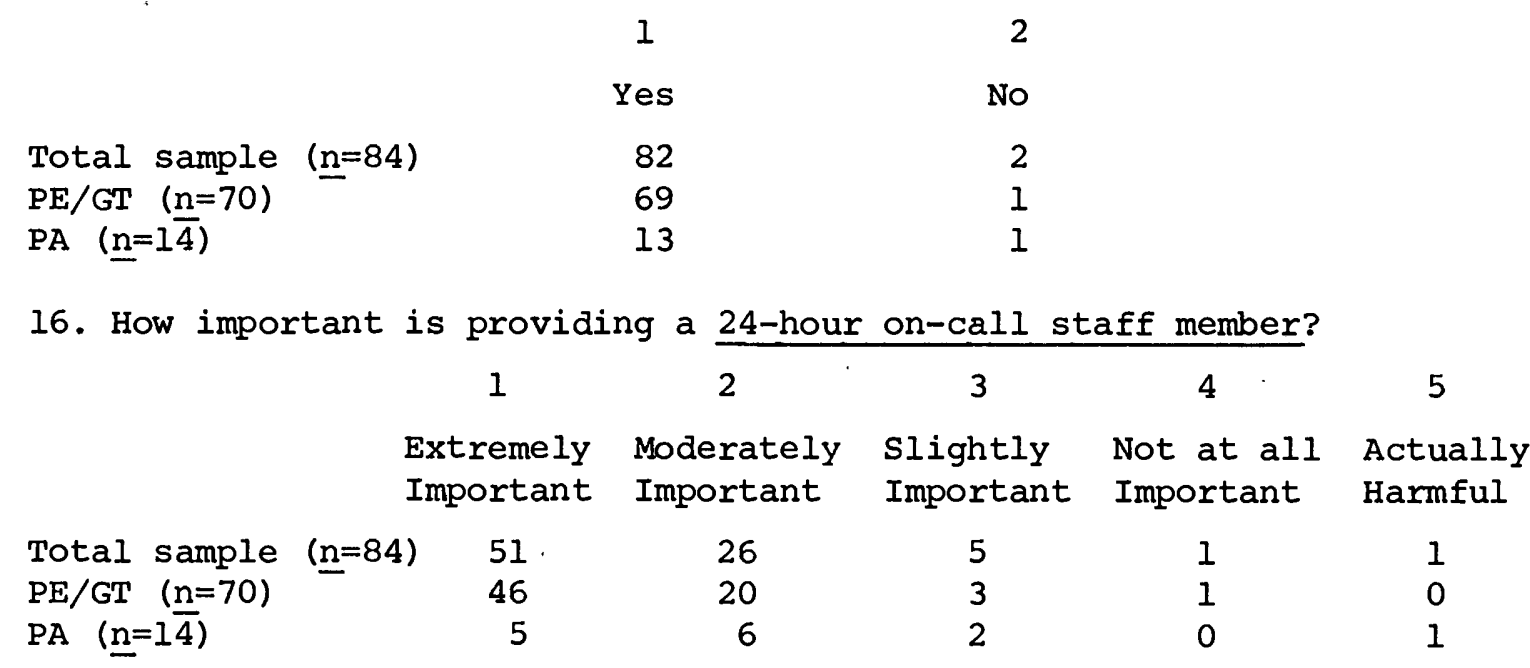

17. Should individual counseling for parents be included in a child abuse treatment program?

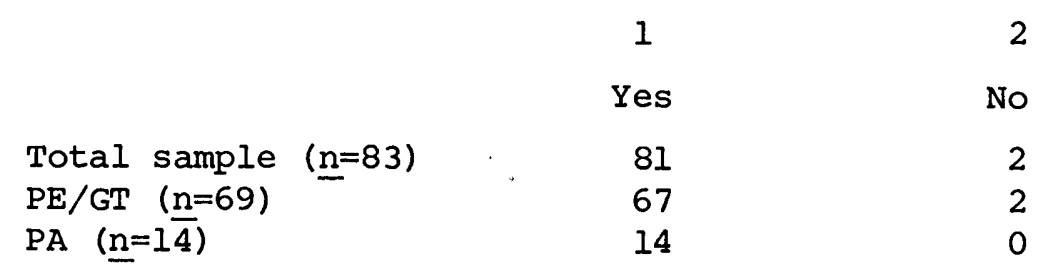

18. How important is individual counseling for parents in this kind of program?
1
2
3
4
5

Extremely Moderately Slightly Not at all Actually Important Important Important Important Harmful

\begin{tabular}{|c|c|c|c|c|c|}
\hline Total sample $(\underline{n}=84)$ & 66 & 16 & 1 & 1 & 0 \\
\hline $\mathrm{PE} / \mathrm{GT} \quad(\underline{n}=71)$ & 57 & 12 & 1 & 1 & 0 \\
\hline $\mathrm{PA} \quad(\underline{n}=1 \overline{3})$ & 9 & 4 & 0 & 0 & 0 \\
\hline
\end{tabular}


APPENDIX B (Continued)

19. Should marital counseling be included in a child abuse treatment program?

1
Yes

Total sample $(\underline{n}=85)$

84

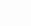

$\mathrm{PE} / \mathrm{GT} \quad(\underline{\mathrm{n}}=71)$

70

$\mathrm{PA}(\mathrm{n}=1 \overline{4})$

14

2

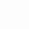

20. How important is marital counseling in a child abuse treatment program?

$$
12 \quad 3 \quad 4 \quad 5
$$

Extremely Moderately slightly Not at all Actually Important Important Important Important Harmful

$\begin{array}{lrrrrr}\text { Total sample }(n=85) & 48 & 26 & 10 & 1 & 0 \\ \text { PE/GT }(n=71) & 40 & 23 & 7 & 1 & 0 \\ \text { PA }(\underline{n}=1 \overline{4}) & 8 & 3 & 3 & 0 & 0\end{array}$

21. Should family therapy be included in a child abuse treatment program? 1 2 Yes No

Total sample $(\underline{n}=85)$

83

No

$\mathrm{PE} / \mathrm{GT} \quad(n=71)$

70

13

1

PA $(n=1 \overline{4})$

1

22. How important is family therapy as a component in this kind of program?
1
2
3
4
5

Extremely Moderately slightly Not at all Actually Important Important Important Important Harmful

\begin{tabular}{|c|c|c|c|c|c|}
\hline Total sample $(\underline{n}=85)$ & 63 & 16 & 6 & 0 & 0 \\
\hline$P E / G T \quad(n=71)$ & 52 & 15 & 4 & 0 & 0 \\
\hline $\mathrm{PA} \quad(n=1 \overline{4})$ & 11 & 1 & 2 & 0 & 0 \\
\hline
\end{tabular}

23. Should parent group therapy be included in a child abuse treatment program?

1

Yes No

Total sample $(\underline{n}=82)$

81.

$\mathrm{PE} / \mathrm{GT} \quad(n=68)$

67

$\mathrm{PA}(\underline{n}=1 \overline{4})$

14

1

1

0 


\section{APPENDIX B (Continued)}

24. How important is parent group therapy in this kind of program?

$\begin{array}{lllll}1 & 2 & 3 & 4 & 5\end{array}$

Extremely Moderately Slightly Not at all Actually Important Important Important Important Harmful

$\begin{array}{lrrlll}\text { Total sample }(\underline{n}=83) & 46 & 33 & 4 & 0 & 0 \\ \text { PE/GT }(\underline{n}=69) & 38 & 27 & 4 & 0 & 0 \\ \text { PA }(\underline{n}=14) & 8 & 6 & 0 & 0 & 0\end{array}$

Group therapy is one component of a child abuse treatment program. The following questions deal with group dynamics issues such as: size of group, homogeneity vs. heterogeneity, open-access groups vs. closedaccess group, time-limited group therapy vs. open-ended group therapy, voluntary group attendance vs. mandatory group attendance, broad focus vs. narrow focus, self-help vs. professional help, screening parents before group attendance, self-disclosure, the group as a support system, and who should lead the groups. Again, please circle your response.

25. Group therapy can be done with small groups of 5-10 people, mediumsized groups of 10-15 people or large groups where there are more than 15 people. Which size group do you prefer?

$$
\text { 5-10 10-15 Over } 15
$$

Total sample $(\underline{n}=80)$

$\mathrm{PE} / \mathrm{GT} \quad(\underline{n}=66)$

PA $(\underline{n}=1 \overline{4})$

70

10

0

56

10

0

26. How important is the size of the group?

123

34

5

Extremely Moderately Slightly Not at all Actually Important Important Important Important Harmful

Total sample $(\underline{n}=79) \quad 38$

$\mathrm{PE} / \mathrm{GT} \quad(n=66)$

$\mathrm{PA}(\underline{n}=1 \overline{3})$

25

9
34

25

9

7
7
0

7

0
0

0

0
0

0

0

27. Group therapy can be done with a homogeneous group where all group members have a common reason for being there or in heterogeneous groups where the members may have different reasons for attending. Do you prefer homogeneous groups where all members have child abuse as a common reason for group attendance or heterogeneous groups 
APPENDIX B (Continued)

where group members have various reasons for attendance?

Homogeneity

Heterogeneity

Total sample $(\underline{n}=74)$

58

16

$\mathrm{PE} / \mathrm{GT} \quad(\underline{\mathrm{n}}=61)$

46

15

$\operatorname{PA}(\underline{n}=1 \overline{3})$

12

1

28. How important is the group issue of homogeneity vs. heterogeneity?

1

2

3

4

5

Extremely Moderately Slightly Not at all Actually

Important Important Important Important Harmful

$\begin{array}{lrrrrr}\text { Total sample }(n=77) & 22 & 36 & 16 & 3 & 0 \\ \text { PE/GT }(\underline{n}=64) & 17 & 32 & 12 & 3 & 0 \\ \text { PA }(\underline{n}=1 \overline{3}) & 5 & 4 & 4 & 0 & 0\end{array}$

29. Group therapy can be done with open groups where parents can start and stop attendance according to their needs and judgement or with closed-access groups where once the group begins, only those initially in the group attend, usually for a specified length of time. Do you prefer open-access or closed-access groups?

\section{Open-access groups Closed-access groups}

$\begin{array}{llr}\text { Total sample }(n=75) & 40 & 35 \\ \text { PE/GT }(n=62) & 30 & 32 \\ \text { PA }(\underline{n}=1 \overline{3}) & 10 & 3\end{array}$

30. How important is the issue of open-access groups vs. closed-access groups?

12535

Extremely Moderately slightly Not at all Actually Important Important Important Important Harmful

$\begin{array}{lrrrrr}\text { Total sample }(n=78) & 18 & 33 & 25 & 2 & 0 \\ \text { PE/GT }(\underline{n}=65) & 14 & 29 & 20 & 2 & 0 \\ \text { PA }(\underline{n}=13) & 4 & 4 & 5 & 0 & 0\end{array}$

31. Group therapy can be time-limited with a predetermined number of group sessions scheduled or it can be open-ended and go on for as long as the group members and/or group leaders want it to. Do you prefer time-limited or open-ended group therapy?

Time-limited

Total sample $(\underline{n}=77)$

$\mathrm{PE} / \mathrm{GT} \quad(n=64)$

$\mathrm{PA} \quad(\underline{n}=1 \overline{3})$
33

30

3
Open-ended

10 
32. How important is the issue of time-limited vs. open-ended group therapy in working with abusive parents?

$\begin{array}{lllll}1 & 2 & 3 & 4 & 5\end{array}$

Extremely Moderately Slightly Not at all Actually

Important Important Important Important Harmful

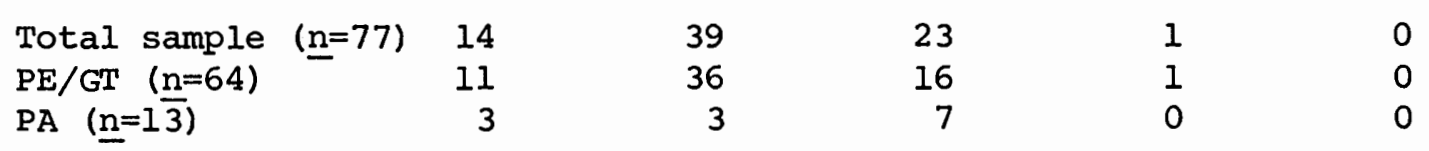

33. Group therapy attendance can be voluntary where parents come when and if they wish or mandatory, either by court or protective service order, or by the rules of the group itself which could state that once a person misses a session he is out of the group. Do you prefer mandatory or voluntary attendance?

$$
\text { voluntary Mandatory }
$$

Total sample $(\underline{n}=74) \quad 52 \quad 22$

$\mathrm{PE} / \mathrm{GT}(\mathrm{n}=61) \quad 39 \quad 22$

$\mathrm{PA}(\underline{n}=1 \overline{3}) \quad 13 \quad 0$

34. How important is the issue of voluntary vs. mandatory attendance?

1

2

3

4

5

Extremely Moderately Slightly Not at all Actually Important Important Important Important Harmful

$\begin{array}{lrrrrl}\text { Total sample }(\underline{n}=77) & 27 & 36 & 12 & 2 & 0 \\ \text { PE/GT }(\underline{n}=64) & 25 & 27 & 11 & 1 & 0 \\ \text { PA }(\underline{n}=1 \overline{3}) & 2 & 9 & 1 & 1 & 0\end{array}$

35. Group therapy can be done with a broad focus of group issues where issues not necessarily related to child abuse are discussed as well as child abuse or group therapy can be done with a narrow focus where discussion centers on child abuse. Do you prefer broad focus or narrow focus groups?

Broad focus

Total sample $(\underline{n}=75)$

$\mathrm{PE} / \mathrm{GT} \quad(n=62)$

$\mathrm{PA}(\underline{\mathrm{n}}=1 \overline{3})$
59

10
Narrow focus

16

13

3

36. How important is the issue of broad focus in the group vs. narrow focus in the group?

1

2

3

4

5

Extremely Moderately Slightly Not at all Actually

Important Important Important Important Harmful

Total sample $(\underline{n}=76) \quad 25$

$\mathrm{PE} / \mathrm{GT} \quad(\mathrm{n}=63) \quad 21$

PA $(\underline{n}=1 \overline{3})$

35

31

4
15

10

5
1

1

0
0

0 
37. Group therapy can be done with the emphasis being placed on the group process or interaction or group therapy can be done with the emphasis placed on the individual. Do you prefer groups with emphasis on the individual or groups with emphasis on the group?

Emphasis on the group Emphasis on the individual

Total sample $(\underline{n}=65)$

$\mathrm{PE} / \mathrm{GT} \quad(\mathrm{n}=55)$

$P A(\underline{n}=1 \overline{0})$
30

26

4
35

29

38. How important is the issue of group therapy with emphasis on the group vs. group therapy with emphasis on the individual?

1 2

Extremely Moderately Important Important 3

Slightly Important
4 5
Total sample ( $\underline{n}=73)$

$\mathrm{PE} / \mathrm{GT} \quad(n=61)$

PA $(\underline{n}=1 \overline{2})$
13

12.

1
39

32

7
18

14

4
Not at all Actually Important Harmful

39. Self-help groups use abusive or formerly abusive parents as leaders or co-leaders of the group. Do you prefer self-help groups or ones that are led by professionals?

Self-help groups Professionally led groups

$\begin{array}{lrr}\text { Total sample }(\underline{n}=67) & 25 & 42 \\ \text { PE/GT (n=55) } & 17 & 38 \\ \text { PA }(\underline{n}=12) & 8 & 4\end{array}$

40. How important is the issue of self-help vs. professionally led groups?

$\begin{array}{lllll}1 & 2 & 3 & 4 & 5\end{array}$

Extremely Moderately Slightly Not at all Actually Important Important Important Important Harmful

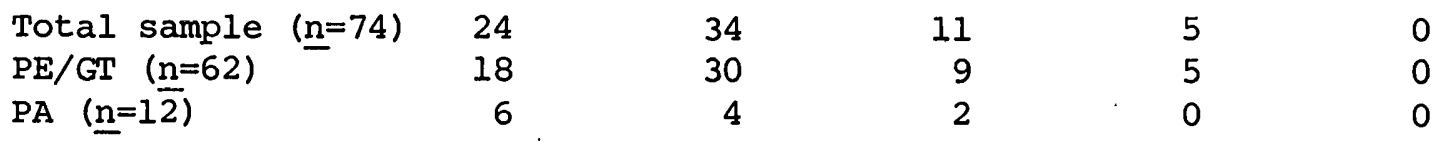

41. Should parents be screened before they are admitted to a group to see if they will be able to relate and participate?

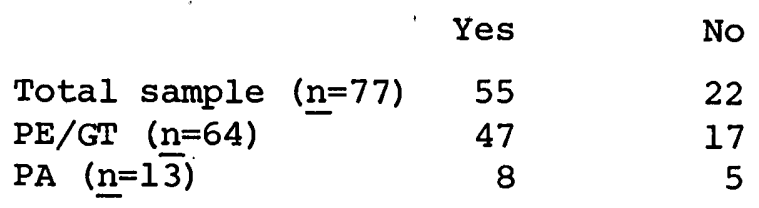




\section{APPENDIX B (Continued)}

42. How important is screening parents before admission to a group composed of abusive parents?

$$
1 \quad 2 \quad 3 \quad 4 \quad 5
$$

Extremely Moderately Slightly Not at all Actually

Important Important Important Important Harmful

\begin{tabular}{|c|c|c|c|c|}
\hline Total sample $(n=78)$ & 26 & 26 & 11 & 13 \\
\hline $\mathrm{PE} / \mathrm{GT} \quad(\underline{n}=65)$ & 24 & 20 & 10 & 10 \\
\hline PA $(n=1 \overline{3})$ & 2 & 6 & 1 & 3 \\
\hline
\end{tabular}

43. Do you think group therapy provides a support system in terms of social contacts and peer support for abusive parents?

\begin{tabular}{|c|c|}
\hline & Yes \\
\hline Total sample $(\underline{n}=79)$ & 78 \\
\hline $\mathrm{PE} / \mathrm{GT} \quad(\mathrm{n}=66)$ & 61 \\
\hline $\mathrm{PA} \quad(\underline{n}=1 \overline{3})$ & 13 \\
\hline
\end{tabular}

44. How important is this support system as a component of group therapy?

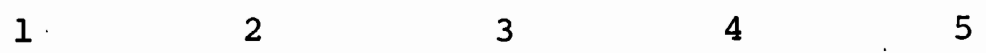

Extremely Moderately Slightly Not at all Actually

Important Important Important Important Harmful

$\begin{array}{llrlll}\text { Total sample }(n=79) & 50 & 24 & 4 & 1 & 0 \\ \text { PE/GT }(n=66) & 40 & 22 & 3 & 1 & 0 \\ \text { PA }(\underline{n}=1 \overline{3}) & 10 & 2 & 1 & 0 & 0\end{array}$

45. Does self-disclosure or a parent talking about his/her own personal abuse problems and feelings aid his/her own individual progress within the group?

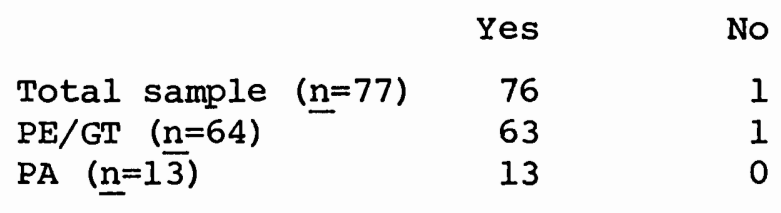

46. Does self-disclosure or a parent talking about his/her own personal abuse problems and feelings aid group process?

$$
\text { Yes No }
$$

Total sample $(\underline{\mathrm{n}}=76) \quad 75 \quad 1$

$\mathrm{PE} / \mathrm{GT}(\mathrm{n}=63)-62 \quad 1$

$\mathrm{PA}(\underline{\mathrm{n}=1 \overline{3})} \quad 13 \quad 0$ 
APPENDIX B (Continued)

47. How important is self-disclosure in group therapy?

$$
\begin{array}{lllll}
1 & 2 & 3 & 4 & 5
\end{array}
$$

Extremely Moderately slightly Not at all Actually Important Important Important Important Harmful

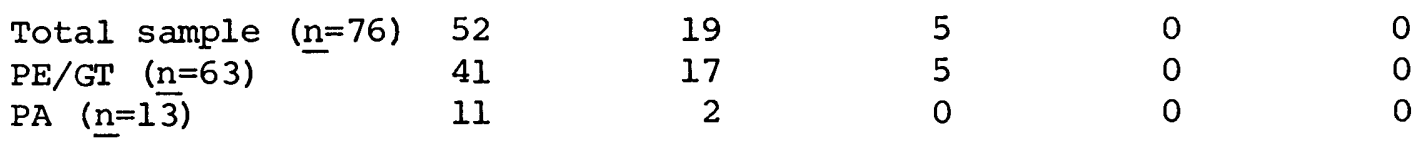

48. Group therapy can be done with one leader or therapist or with co-leaders or therapists. Do you prefer one therapist/leader or co-therapists or co-therapists/leaders?

$$
\text { One therapist/leader Co-therapists/leaders }
$$

$\begin{array}{lrrr}\text { Total sample }(\underline{n}=73) & 10 & 63 \\ \mathrm{PE} / \mathrm{GT}(\mathrm{n}=61) & 8 & 53 \\ \mathrm{PA}(\underline{\mathrm{n}}=1 \overline{2}) & 2 & 10\end{array}$

49. How important is the issue of 1 therapist/leader vs. co-therapists/ leaders?
1
2
3
4
5

Extremely Moderately slightly Not at all Actually Important Important Important Important Harmful

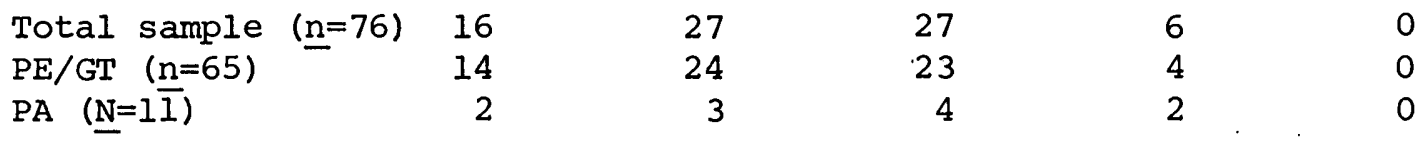

50. If a group is led by co-therapists should they both be professionals, both nonprofessionals or one professional and one nonprofessional?

Both professionals Both nonprofessionals one each

$\begin{array}{lrrrr}\text { Total sample }(n=64) & 28 & 1 & 35 \\ \text { PE/GT }(n=54) & 24 & 1 & 29 \\ \text { PA }(\underline{n}=10) & 4 & 0 & 6\end{array}$

51. How important is the issue of co-leaders being both professionals, both nonprofessionals or one professional and one nonprofessional?

1

2

3

4

5

Extremely Moderately slightly Not at all Actually Important Important Important Important Harmful

$\begin{array}{lrrrrr}\text { Total sample }(\underline{n}=77) & 10 & 32 & 27 & 8 & 0 \\ \mathrm{PE} / \mathrm{GT} \quad(\underline{n}=66) & 8 & 30 & 21 & 7 & 0 \\ \mathrm{PA}(\underline{n}=1 \bar{l}) & 2 & 2 & 6 & 1 & 0\end{array}$




\section{APPENDIX B (Continued)}

52. Co-therapists who conduct group therapy may be of the same or opposite sex. Do you prefer male-female co-therapists or both therapists of the same sex?

Male-female co-therapists Both therapists same sex

Total sampel $(\underline{n}=71)$

$\mathrm{PE} / \mathrm{GT} \quad(\mathrm{n}=61)$

PA $(\underline{n}=1 \overline{0})$
67

10
4

4

53. How important is the issue of male-female co-therapists vs. both therapists of the same sex?

1

2

3

4

5

Extremely Moderately slightly Not at all Actually Important Important Important Important Harmful

$\begin{array}{lrrrrr}\text { Total sample }(n=75) & 11 & 28 & 29 & 7 & 0 \\ \text { PE/GT }(n=64) & 10 & 25 & 26 & 3 & 0 \\ \text { PA }(\underline{n}=1 \bar{l}) & 1 & 3 & 3 & 4 & 0\end{array}$

54. Put in order of importance ( 1 being the most important, 2 the next most important,...) the following group dynamics issues.

size of group

homogeneity vs. heterogenity

closed-access vs, open-access

time-limited vs. open-ended

voluntary vs. mandatory

broad focus vs. narrow focus

group therapy with individual emphasis or group therapy with group emphasis

self-help vs. professionally led groups

self-disclosure

the group as a support system

co-leaders who are either both professionals, both nonprofessionals or one of each

one therapist/leader vs. co-therapists/leaders

male-female co-therapists vs. co-therapists of the same sex

See Table 4: Total sample Median ranks in Result section; see

Table 5: $\mathrm{PE} / \mathrm{GT}$ and $\mathrm{PA}$ Median ranks in Result section.

55. Put in order of preference ( 1 being the one you most prefer, 2 being the next,...) the following orientations of conducting group therapy with child abusers.

transactional analysis

behavior mod/social learning

psychoanalytic didactic/teaching/lecture eclectic

See Table 6: Total sample Median ranks in Result section; see Table 7: PE/GT and PA Median ranks in Result section. 


\section{APPENDIX B (Continued)}

Parent education where parents learn about child care, family relations, and child development is another specific component of child abuse treatment programs. The following questions refer to the settings in which parent education can be conducted, such as hospital, community, parents' home or milieu environment. There are also questions referring to the methodology used in parent education, such as psychoanalytic, behavior modification/social learning, transactional analysis, didactic, home visits, parent child interaction sessions, self-monitoring, and groups.

56. Should parent education be included in a child abuse treatment program?

Yes No

Total sample $(\underline{n}=83) \quad 83 \quad 0$

$\mathrm{PE} / \mathrm{GT}(\mathrm{n}=71) \quad 71 \quad 0$

$\mathrm{PA}(\underline{\mathrm{n}}=1 \overline{2}) \quad 12 \quad 0$

57. How important is parent education in this kind of program?

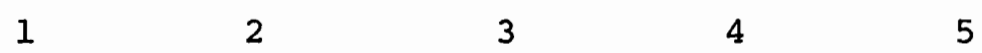

Extremely Moderately slightly Not at all Actually Important Important Important Important Harmful

\begin{tabular}{|c|c|c|c|c|}
\hline Total sample $(\underline{n}=84)$ & 64 & 17 & 3 & 0 \\
\hline $\mathrm{PE} / \mathrm{GT} \quad(\mathrm{n}=71)$ & 54 & 16 & 1 & 0 \\
\hline $\mathrm{PA} \quad(n=1 \overline{3})$ & 10 & 1 & 2 & 0 \\
\hline
\end{tabular}

58. Can parent education be adequately conducted in a community/social agency setting?

Yes No

Total sample $(\underline{n}=83) \quad 80 \quad 3$

$\mathrm{PE} / \mathrm{GT}(\underline{n}=71)-68 \quad 3$

$\mathrm{PA}(\underline{\mathrm{n}}=1 \overline{2}) \quad 12 \quad \cdot 0$

59. Can parent education be adequately conducted in a hospital setting? Yes No.

Total sample $(\underline{n}=79) \quad 61 \quad 18$

$\mathrm{PE} / \mathrm{GT}(\underline{n}=68) \quad 52 \quad 16$

PA $(\underline{n}=1 \overline{1})$ 


\section{APPENDIX B (Continued)}

60. Can parent education be adequately conducted in the home of the abusive parent?

$\begin{array}{lrr} & \text { Yes } & \text { No } \\ \text { Total sample }(\underline{n}=79) & 64 & 15 \\ \text { PE/GT }(\underline{n}=67) & 53 & 14 \\ \text { PA }(\underline{n}=12) & 11 & 1\end{array}$

61. Put in order of importance ( 1 being the most effective, 2 the next most effective,...) the setting for parent education. milieu

- community/social agency hospital other (Specify)

See Table 8: Total sample Median ranks in Results section; see Table 9: PE/GT and PA samples Median ranks in Results section

62. How effective do you think parent education would be if done using behavior modification/social learning methods?

$$
\begin{array}{lllll}
1 & 2 & 3 & 4 & 5
\end{array}
$$

Extremely Moderately Slightly Not at all Actually Effective Effective Effective Effective Harmful

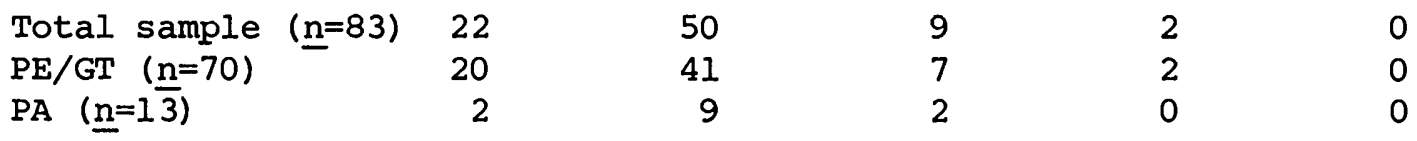

63. How effective do you think parent education would be if done using psychoanalytic methods?
1
2
3
4
5

Extremely Moderately Slightly Not at all Actually Effective Effective Effective Effective Harmful

$\begin{array}{llrrrr}\text { Total sample }(\underline{n}=81) & 4 & 27 & 31 & 17 & 2 \\ \mathrm{PE} / \mathrm{GT}(\underline{n}=70) & 4 & 23 & 26 & 15 & 2 \\ \mathrm{PA}(\underline{\mathrm{n}}=1 \overline{1}) & 0 & 4 & 5 & 2 & 0\end{array}$

64. How effective do you think parent education would be if done using transactional analysis?
1
2
3
4
5

Extremely Moderately Slightly Not at all Actually Effective Effective Effective Effective Harmful

$\begin{array}{lrrrrr}\text { Total sample }(n=83) & 14 & 41 & 19 & 9 & 0 \\ \text { PE/GT }(n=70) & 12 & 36 & 15 & 7 & 0 \\ P A(\underline{n}=12) & 2 & 5 & 4 & 1 & 0\end{array}$




\section{APPENDIX B (Continued)}

65. How effective do you think parent education would be if done using didactic or teaching/lecture methods?

$$
\begin{array}{lllll}
1 & 2 & 3 & 4 & 5
\end{array}
$$

Extremely Moderately Slightly Not at all Actually Effective Effective Effective Effective Harmful

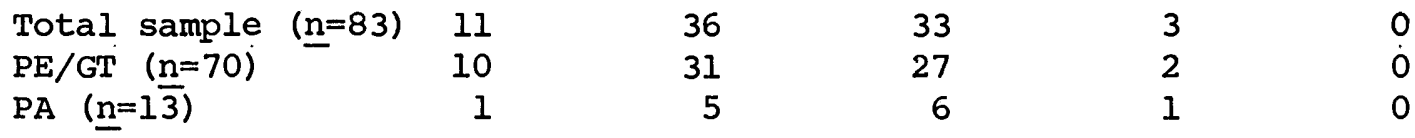

66. How effective do you think parent education would be if done using home visits where the educator goes into the parents' home to give instructions?

1203045

Extremely Moderately slightly Not at all Actually Effective Effective Effective Effective Harmful

$\begin{array}{lrrrrr}\text { Total sample }(n=82) & 31 & 42 & 8 & 1 & 0 \\ \text { PE/GT }(\underline{n}=70) & 28 & 34 & 7 & 1 & 0 \\ \text { PA }(\underline{n}=1 \overline{2}) & 3 & 8 & 1 & 0 & 0\end{array}$

67. How effective do you think parent education would be if done using parent-child interaction sessions?

$\begin{array}{lllll}1 & 2 & 3 & 4 & 5\end{array}$

Extremely Moderately slightly Not at all Actually Effective Effective Effective Effective Harmful

\begin{tabular}{|c|c|c|c|c|}
\hline Total sample $(\underline{n}=82)$ & 35 & 42 & 4 & 1 \\
\hline $\mathrm{PE} / \mathrm{GT} \quad(\underline{n}=70)$ & 30 & 35 & 4 & 1 \\
\hline $\mathrm{PA} \quad(n=1 \overline{2})$ & 5 & 7 & 0 & 0 \\
\hline
\end{tabular}

68. How effective do you think parent education would be if done by teaching parents how to monitor themselves in terms of their behavior towards their children?

1

2

3

4

Extremely Moderately Slightly Not at all Actually Effective Effective Effective Effective Harmful

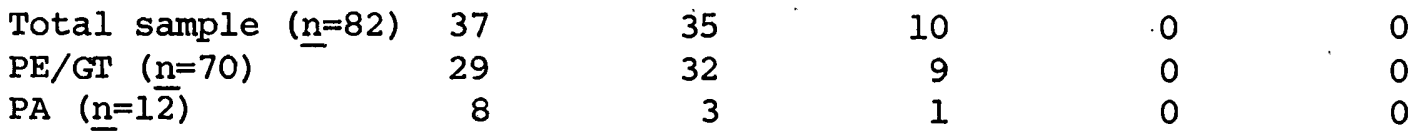




\section{APPENDIX B (Continued)}

69. How effective do you think parent education would be if done in groups?

$$
\begin{array}{lllll}
1 & 2 & 3 & 4 & 5
\end{array}
$$

Extremely Moderately Slightly Not at all Actually Effective Effective Effective Effective Harmful

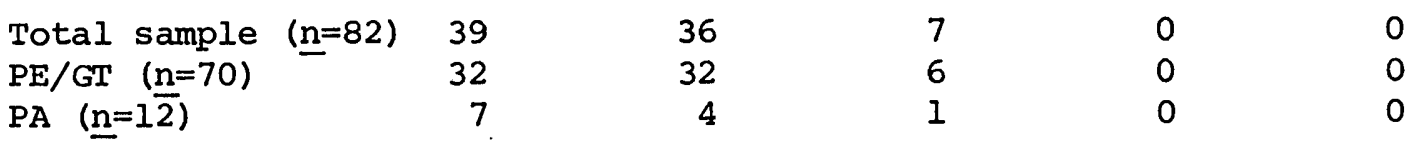

70. How effective do you think parent education would be if done using eclectic methods?

1

2

3

4

5

Extremely Moderately Slightly Not at all Actually Effective Effective Effective Effective Harmful

Total sample $(\underline{n}=78) \quad 28$

$\mathrm{PE} / \mathrm{GT} \quad(\mathrm{n}=66)$

$P A . \underline{n}=1 \overline{2})$
22

6
35

31

4
15

13

2

$\begin{array}{ll}0 & 0 \\ 0 & 0 \\ 0 & 0\end{array}$

71. Put in order of preference ( 1 being the one you most prefer, 2 being the next,....) the following orientations of parent education with child abusers.

transactional analysis

transactional analysis
behavior modification/social learning
psychoanalytic
eclectic
self-monitoring
group
parent-child interaction sessions
didactic/teaching/lecture
home visits

See Table 10: Total sample Median ranks in Results section; see Table 1l: $\mathrm{PE} / \mathrm{GT}$ and $\mathrm{PA}$ samples Median ranks in Results section.

72. Put in order of importance ( 1 being the most important, 2 the next most important,...) the following components of parent education. health care

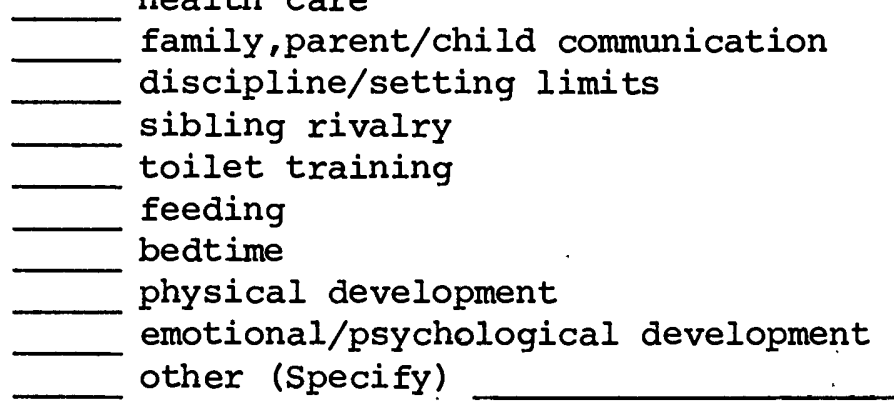


See Table 12: Total sample Median ranks in Results section; see Table 13: PE/GT and PA samples Median ranks in Results section.

Please make any comments you have regarding the questionnaire in the following space: 


\section{APPENDIX C \\ FOLLOW-UP LETTER}

November, 1968

Dear Program Director:

I am working on a Master's degree in Psychology at Portland State University. Currently I am working on my thesis in the area of child abuse and neglect. In september I sent you a questionnaire concerning this subject. The questionnaire dealt specifically with group therapy and parent education for child abusers.

Approximately 408 of the questionnaires I sent out have been returned. The questionnaire results would be more useful if there was a higher rate of return, so I am following up on those questionnaires that have not been returned.

I realize that I sent the questionnaire at the end of summer and that due to vacations, misrouting and time demands there might not have been a chance to respond to the questionnaire. It would be extremely helpful to me in completing my thesis work, however, if you would return the enclosed card with the appropriate response checked. As stated on the card, I would be happy to send you another one if the original has been misplaced.

Thank you.

Jane Crawford

Psychology Graduate Student

3278 S.E. Ankeny

Portland, OR 97214 


\section{APPENDIX D \\ FOLLOW-UP POSTCARD}

Have misplaced quest. but please send another. Address :

Quest. is currently being filled out by: (Name of respondent)

Do not have parent ed. or group therapy.

Received quest. but do not wish to respond. 


\section{APPENDIX E}

\section{PRACTITIONER COMMENTS}

The following is a summary of comments made by practitioners who responded to the questionnaire.

(1) Components described in child abuse treatment programs do not need to be provided by a child abuse treatment agency. "They should, however, be available in a network of community resources."

(2) Questions regarding group dynamics difficult to answer in a general way since: (1) the type of group; (2) the purpose of the group; (3) the clients; and (4) the therapist all affect the answers to these questions.

(3) There are too many variables in working with human beings to safely say any one method is best.

(4) Questions are difficult to answer in a general way because the answer depends on the client. (Two respondents made this comment.)

(5) In working with abusive families three things should be considered: (1) home education; (2) use of a visiting nurse; and (3) counseling for foster and stepparents. 
(6) In my experience, individual supportive work with. abusive parents, such as might be done with a parent aide, family friend, homemaker or home teacher, should receive a far higher priority in program development than group work. Group therapy is a modality which such parents are able to make use of only after considerable work with overcoming social isolation and low ego strength.

(7) I find the answers in the 5-level responses too broad and non-specific to really indicate what my feelings on most issues are. (Several respondents made this comment.)

(8) Family counseling and marital counseling are important but usually the individuals in these families are not ready for interactions of this kind and need a lot of individual attention first.

There is a good deal of difference between education for parents and treatment for parents. Both are important, neither can be left out. Treatment methods must include behavioral, affective and cognitive components. Transactional analysis uses all three approaches. You cannot call any of these treatments "Parent Education" which is really more based on knowledge about child development, etc. So I had difficulty with your questionnaire which seems to attempt to equate these very different things.

(9). I would have answered a number of these questions differently had you included the word "prevention" of 
child abuse.

(10) Questionnaire was answered by a worker in office of community of 8,000 . This size prohibits enacting some procedures that are good. I think group work has its place, but in a small community there can be no "secrets". There needs to be some degree of identity secrecy in group work, at least in the beginning.

(11) I have some reservations about the usefulness of your questionnaire. I think it is important to know one's own bias and background, but I think the way your questions are asked will only serve to prove that which you already believe. I doubt if you will receive answers that doubt the usefulness of all supports available to persons in crisis. ( $I$ consider child abuse to be a symptom of crisis.) So all collateral supports--Peer Professional, Day Care, Education, Therapy, etc.--are valuable. The question that needs intensive study is how valuable--measures of a control group and groups receiving various services (I recognize the ethical dilemmas presented in such designs). I believe we need these answers on other than belief or value basis in order to concentrate our energies rather than scatter them. Economic funding is so difficult to maintain today, that such answers become even more important. It will be a rare program that can provide all the support areas you have touched on. 
(12) Much of the questionnaire has dealt with programs which require a catchment area quite a bit larger than the 4,000 people in the rural county that I serve. When we have a program at all, it is a one-person "boot-strap" operation. What I would need, is information regarding program implementation in a rural area. As you may know, there is precious little data on rural social services pertaining to child protective services.

(13) The categories ought to be less overlapping. Questionnaire too lengthy.

(14) An interesting and helpful study.

(15) This is a very well thought questionnaire. I have done some research in the area of abuse (factors) and I'm still working on some of these related problems.

(16) Regarding question 28 our experience has indicated that homogeneous groups are more effective in dealing with prevention of further abuse and protection of the child. Regarding question 50, we believe that a group needs leaders that have both theoretical and practical experience.

(17) I had trouble with the questionnaire format. I feel child abuse has little to do with a person's hangups and a lot to do with what is going on in their life and how they and those around them are trying to cope. Thus a woman may be unable to be happy in her marriage but because of 
problems in her upbringing and without skills she is unable to terminate her marriage. In addition, her children cause problems which give her a target to vent her anger, blame for her problems. This isolates the family which further prevents the mother from leaving the situation.

(18) I believe home visits in conjunction with other methods are extremely important.

(19) While we are a small rural county Social Service Agency we try and provide as many resources as possible. We have individual counseling, family counseling, marital counseling, emergency child care, day care, home visits, 24-hour on-call staff, parenting classes and medical programs as well as homemaker and home health aides. I would highly recommend to you, the use of homemakers in a treatment program.

(20) I feel child abuse treatment programs must be different in each community to meet the needs of the community. I had a difficult time defining the terms "extremely, moderately, and.slightly" in a general sense to cover any community. I had problems rank-ordering questions 54, 72, and 73. I think all the items are important to each question asked--it would be more helpful to check $(\checkmark)$ those which would be most important, rather than rank-order them.

(21) You make little reference to the poor tharital relationship which causes children to be scapegoated. 
(22) On question 73 crisis help was given first priority.

(23) I think you should know that abuse cases we come in contact with are reported to local Department of Social Service and to Child Protective Service. When a referral is made, we find that virtually nothing is done. I assume this is because workers have no authority in such cases. I have reported incest and been told it is not a crime in the state. I have seen bruises from beatings, reported it and have been told a worker will be assigned to check it out-only to learn a week later that no worker had been assigned yet. I have talked with local church people regarding abuse within a family in the parish and have been told parents have a right to raise children as they see fit. My experiences with agencies whose primary focus is to deal with abuse is that they are all talk and no do.

(24) The structure tends to eliminate real discrimination among alternatives except in ranking sections. With the rankings the rest of the questions seem unnecessary.

(25) A perfect total child abuse program would include all of the programs in question 73. Problems with including all of these would involve number of staff and financial resources. Coordination would have to be excellent.

(26) The questionnaire does not distinguish between the variety of groups that can be offered parents--support 
groups, self-help groups differ greatly from therapy or parent education so the general questions in group process were difficult to answer.

(27) A lot of your ranking was very difficult to do since you're given fantasy free reign and asking what's ideal. In many cases P.A. is ideal, but it sure would be nice to have more crisis nurseries, therapeutic daycare, and preventative parent education available. I really believe strongly that the more a family has available simultaneously, the better (and faster) the chances of improvement are. You didn't ask about confidentiality, and I think that for parents to get anything out of any program they must feel safe or they won't risk the honesty required to really progress.

(28) I'm not sure you will come up with anything you do not already know or could not have gained from five interviews.

(29) We have tried for a long time to coordinate treatment in this community. Coordination of case-finding, acute care and education are working well; but coordination of long term treatment is a long way off.

(30) Regarding question 1: Day care is extremely important when the parent wants it, but I do not think parental authority should be taken from the parents (I am not speaking of those who have abused their children repeatedly 
without effective personal effort to change).

Regarding question 40: Parents appear to deal more easily with leaders whether professional or non-professional who have had similar life experiences. 